MA Master's Research Paper

\title{
The Transformation of Network Neutrality in Canada
}

\author{
By: Natalie Andrusko \\ Student Number: \\ Supervisor: Dr. Catherine Middleton (Ryerson University) \\ Second Reader: Dr. Fred Fletcher (York University)
}

A Master's Research Paper submitted

in partial fulfilment of the requirements for the degree of Master of Arts

Joint Graduate Program in Communication \& Culture

York University-Ryerson Polytechnic University

Toronto, Ontario, Canada 
TABLE OF CONTENTS

\begin{tabular}{|c|c|}
\hline Page\# & Topic \\
\hline 1 & Introduction to Main Themes and Topics \\
\hline 6 & A Brief History of Internet Neutrality in Canada \\
\hline 12 & Literature Review \\
\hline 19 & Conclusions Regarding Literature in the Field \\
\hline 22 & Introduction to Primary Research \\
\hline 23 & Content Analysis Framework \\
\hline 28 & $\begin{array}{l}\text { Values of Stakeholders at the CRTC Hearing - Content } \\
\text { Analysis } 1\end{array}$ \\
\hline 43 & Conclusions of Content Analysis 1 \\
\hline 47 & $\begin{array}{l}\text { Key Research Questions and Consistency of Terms } \\
\text { Selected - Content Analysis } 2 \text { and } 3\end{array}$ \\
\hline 51 & Conclusions of Content Analysis 2 and 3 \\
\hline 52 & $\begin{array}{l}\text { Introduction to Critical Discourse Analysis of CRTC } \\
\text { Hearings }\end{array}$ \\
\hline 54 & Findings of Discourse Analysis \\
\hline 64 & $\begin{array}{l}\text { Brief Update on the Internet Neutrality Debate in Canada } \\
\text { since the Traffic Management Practice Hearing Ruling in } \\
\text { October } 2009\end{array}$ \\
\hline 65 & Final Thoughts on Research Findings and Research Goals \\
\hline
\end{tabular}




\section{Author's Note and Acknowledgements}

I first became interested in the topic of Internet neutrality in 2008, after a McMaster professor in my Communication Studies program first presented the topic in a lecture. I was shocked to learn how Internet Service Providers, like Bell and Rogers, manage their broadband networks, and was completely unaware of how Internet neutrality could be an area of telecommunications policy debate that could impact me directly. Millions of Canadians continue to use and subscribe to the Internet, but many are simply unaware of the term 'Internet neutrality.' Since I became familiar with the topic, it has been a personal goal of mine to spread awareness on this topic, and to teach the people around me about how the issue of network neutrality could impact them personally.

Thanks to the joint Communication and Culture program at Ryerson and York University, I had the opportunity to conduct my own primary research on the topic, as well as explore major themes and discussions surrounding the network neutrality debate in Canada. Over the past two years, I have enjoyed meeting all of the program's faculty and students, and I will always remember my time spent in the program.

Also, I would like to thank my supervisor, Dr. Catherine Middleton, and my second reader, Dr. Fred Fletcher, for their help and support in writing this major research paper. Their insight and experience in the telecommunications field proved to be invaluable to my paper's findings.

To conclude, as my time spent as a Masters student winds up, I must state that this paper would not have been possible without the support of my family, friends, and loved ones. You have been a constant source of strength and support throughout the past two years during graduate school, and I will always appreciate how patient you were with me, even during my most stressful moments as a student.

More specifically, thank you Mom, Dad, Nick and Tim. I am so grateful to have such supportive loved ones. You four always encourage me to do my best, and achieve the goals I set for myself, as both a student, and as an individual. I love you four very much!

Again, thank you everyone for all of your support, and I hope you enjoy reading my 'epic' essay on Internet neutrality.

- Natalie Andrusko

Honours B.A. in Communication Studies - McMaster University (2005-2009)

Master of Arts in Communication and Culture - Ryerson/York University (2009-2011) 


\section{The Transformation of Network Neutrality in Canada}

Telecommunications technology hos dramatically transformed an individual's ability to access information. Internet surfers are often unaware of the ways in which their Internet services are being managed, and even fewer are familiar with the term Internet neutrality. As a growing trend, more Internet Service Providers (ISPs) in Canada are intervening with the infrastructure of the Internet by utilizing traffic management practices, such as bandwidth throttling', which hinder a user's ability to quickly access certain types of content online. Internet traffic management practices (ITMP) are a means for ISPs to control their 'congested" networks, with the aim of optimizing or improving their network's performance, or they can often aid in increasing usable bandwidth (Lithgow, 2011). Traffic management practices ultimately allow one kind of 'packet ${ }^{3}$ to be delayed over another; for example, ISPs often use a program called Deep Packet Inspection (DPI), which is a program that can identify forms of traffic online, meaning it can target specific applications. Since ITMPs can target specific 'packets' online, smaller interest groups, and businesses became increasingly concerned that network neutrality policy principles, such as 'common-carriage', was not being enforced by the CRTC. This paper will identify the main concerns of utilizing ITMP on broadband

\footnotetext{
'This is an ITMP that slows down a user's ability to access an application/content online by slowing down the user's Internet speed. Throttling band width is a key concern of many Internet neutrality advocates who do not want certain applications and websites to have slower download/upload speeds for users online.

${ }^{2}$ ISPs in Canada state that their networks cannot handle the amount of traffic occurring on their networks. Also the issue of congestion can be linked to the Internet neutrality debate because ISPS defend the use of ITMP due to 'congestion', and since ITMP concern many network neutrality advocates, the issue of congestion is at the forefront of the debate.

${ }^{3}$ In this context, a packet can be described as a formatted unit of data by a computer network.

${ }^{4}$ Common-carriage is one of the earliest policy measures enacted by the government to ensure equal competition and the fair exchange of goods and information. This term will be further defined in the history of network neutrality portion of this essay.
} 
networks, and will illustrate that ITMP can and should be connected to the discussion regarding network neutrality in Canada.

Particularly, the use of DPI, and other traffic management practices online, is related to the Internet neutrality debate occurring in Canada, since advocates for network neutrality often oppose traffic management practices. Internet neutrality is an area of telecommunications policy that is very unfamiliar to most Canadians, and often overlooked by Canadian scholars. It is essential to examine Internet neutrality because it is a timely and controversial issue that affects a lot of Canadian Internet users. While most scholars who are interested in Internet neutrality tend to focus on the American context, it is vital to provide more insight and research on Canada's Internet neutrality debate, in light of the Canadian Radio and Television (CRTC) hearing on Internet management practices, which took place in July 2009 for seven days in Gatineau, Quebec.

Accordingly, the intention of this research is to identify and explore the major themes and values of various stakeholders who presented at the CRTC hearing on Internet Traffic Management Practices; a hearing that can arguably be considered to offer a discourse that is related to the term 'Internet neutrality'. The transcripts of the CRTC hearing held in 2009 were closely examined and assessed using both qualitative and quantitative research methodologies. A content analysis and a discourse analysis were employed to explore six key underlying values, such as wealth or authority, which influence the perspectives and judgements of the various stakeholders who spoke at the CRTC hearing regarding Internet traffic management practices. To the best of the author's knowledge, no other Canadian academic has explored the hearing in such a 
close regard; the research findings on the hearing are the first of their kind in the Communication Policy field. The findings from the research exemplifies the similarities and differences of values amongst the various stakeholders who spoke at the CRTC hearing, and highlight underlying themes and principles which shape and motivate policy decisions which ultimately impact Canadian Internet users.

Before discussing the CRTC hearing on Internet traffic management practices and how it is related to the Internet neutrality debate, one must define the term 'Internet neutrality.' Although there are numerous definitions of Internet neutrality, as explored in the literature review, for the purpose of this research, Meinrath and Pickard's definition of Internet neutrality will be applied. Meinrath and Pickard's definition was selected after reading a variety of definitions because it provides a very basic framework of what the term encompasses. Internet neutrality forbids the preferential treatment of specific content, services, applications, and devices that can be integrated into the network infrastructure (Meinrath \& Pickard, 2008). Under this assumption, with network neutrality ISPs cannot control the kind of content users are accessing, and cannot impede the users' experience in accessing such content online.

Discrimination is at the core of the Internet neutrality debate, which brings up important policy matters such as, when is it justifiable to discriminate against certain applications online, and how it can grant preferential treatment of some applications over others. As the discourse analysis on the CRTC hearing on Internet traffic management practices will illustrate, it is more aggressive forms of discrimination that fuel the controversy regarding network neutrality. Since Internet neutrality is a complex and 
multifaceted issue, this research paper will mostly focus on the issue of ISPs discriminating certain applications and services online as an Internet neutrality issue.

Also, since large ISPs in Canada, such as Bell and Rogers, also have a stake in the television subscription market, these media conglomerates have a great deal of control over Canadian access to media. Competition is another key theme of this research essay, because Bell and Rogers continue to buy out television networks, which can grant them exclusive rights and access to content that can be re-purposed for online distribution. For example, in 2010, Bell bought CTV, a private broadcasting network for $\$ 1.3$ billion dollars, which is a move that then CEO of CTV Globemedia, Ivan Fecan suggested was an extremely important move for Bell, because it “...can take advantage of content over multiple screens," and it will “...accelerate Bell's video growth across all three screens mobile, online and TV" (CTV.ca, "Bell Canada Parent BCE buys CTV Inc. for \$1.3B", 2010). Consequently, it is important to consider the argument that less Internet neutrality could mean preferential treatment of certain websites (perhaps owned by the ISPs themselves), which would ultimately impact the accessibility of certain information available online. If the Internet is to remain Canada's most democratic and most global medium, a non-neutral network could mean less innovation and it may interfere with a user's ability to connect to diverse news sources and applications online. These issues are major concerns that were addressed by the dialogue during the CRTC hearing on Internet traffic management practices, and will be further discussed in the primary research section of this essay.

Furthermore, the Internet neutrality debate provokes policy and regulatory questions such as: what is the CRTC's stance on this issue, what sort of regulation of the 
Internet should be legislated, and what are the arguments for and against having a neutral network. Also, due to the increasing use of traffic management practices online, and the lack of diverse ownership of ISPs, the topic of Internet neutrality in Canada needs to be further examined by academics in the Communications field. This in-depth study will aid in providing a thorough analysis of the CRTC hearing, which as suggested, is an area of research which has yet to be studied by another Canadian academic. Foremost, the research and literature review provides insight into the issue of how Internet neutrality is wavering as Internet service providers (ISPs) continue to use traffic management practices as a means to control congestion online. The following research illustrates how the Internet traffic management hearing raised interesting research questions such as how competitive is the ISP market, what do smaller businesses and alternative ISPs think of larger ISPs using ITMP such as bandwidth throttling and DPI, and how is Internet neutrality related to ITMP? The research findings conclude that Internet neutrality is a term that is quite relevant to consider in relation to Internet traffic management practices, since ITMP do provide preferential treatment of certain 'packets' over others on networks. ITMP are non-neutral network practices, which advocates of Internet neutrality deem to harm the open architecture ${ }^{5}$ that the Internet was founded upon. The CRTC's decision on Internet traffic management practices is ultimately related to the overall Internet neutrality debate in Canada. The research findings suggest that Internet traffic management practices have allowed ISPs to increase their control over the architecture of the Internet that millions of Canadians subscribe to across the nation.

\footnotetext{
${ }^{5}$ The open architecture of the Internet is a common argument that Internet neutrality advocates utilize in their defence. Since the Internet essentially has no central control, and is made up of interconnected networks of networks, the Internet has always been an open environment, meaning there has been little external interference with how it has been developed over time. Advocates suggest that the Internet has thrived because of its openness and ease of access (Barratt and Shade, 2007).
} 


\section{A Brief History of Internet Neutrality in Canada}

In order to understand how Canada's Internet has become less neutral in the past half decade, one must understand the roots of network neutrality as a common-carriage policy. In the 1800s, American and English governments began applying common carriage rules to the dominant modes of transportation, such as railroads. In the $1900 \mathrm{~s}$, common carrier regulations that were applied to railroads were also extended to telephone and telegraph companies, because it was deemed that, "...the carriage of electronic intelligence should be regulated in the same manner as the carriage of goods and passengers" (Speta, 2002). Common carriage principles implement policies that prevent carriers from influencing messages which flow through their networks, and require carriers to offer non-discriminatory access to their system on the basis of "just and reasonable" rates (Canada, 1979, s. 320; 1993, s. 33). Also these policies limited the carriers' liability for messages communicated through their networks (Canada, 1979, s. 381; Department of Communication, 1971). For example, Section 5 of the Bell Canada Act explicitly states that the company "...shall neither control the contents nor influence the meaning or purpose of the message emitted, transmitted or received" (Canada, 1967). The Telecommunications Act (1993) extended these provisions to all carriers.

Though the Internet neutrality debate has only surfaced in the last decade, as the Internet continues to develop as one of the most utilized mediums, the separation of carriers and content has been a part of telecommunications policy in Canada, as well as in the U.S. In their literature review, Barratt and Shade (2007) also trace the origins of this disassociation as far back as early railway legislation, where this was "...the beginning of 
policy separation between network infrastructures and content that moves over the network." Therefore, the responsibility of the network owner to ensure that data was treated equally, as well as to assure that it was available to other networks, has always been a key aspect of all telecommunication policy debates in Canada, even before the origin of the Internet.

Fundamentally, the practice of common carriage came to the forefront of the Internet regulation debate in Canada when Bell began the practice of "traffic throttling" in 2005. "Traffic throttling" is a form of an ITMP, and occurs when ISPs block and interfere with a subscriber's accessibility to a certain website. Steve Anderson (2009) suggests that, "The importance of net neutrality was made clear in Canada when Bell Canada's traffic 'throttling' began limiting a user's ability to view the CBC's hit show ‘Canada's Next Great Prime Minister." Canadians complained that it took more than a day to download the show and that Bell was limiting accessibility to certain websites, specifically sites that utilized peer-to-peer ${ }^{6}$ downloading programs, such as BitTorrent. This is just one of the many examples of ISPs in Canada "throttling" traffic online and interfering with a user's ability to access content or applications online; furthermore bandwidth throttling is just one example of an Internet traffic management practice that is commonly utilized by ISPs in Canada.

Internet traffic management practices, such as throttling, are closely connected to the Internet neutrality debate because they interfere with the open architecture of the Internet; in the past, many of the Internet's most popular applications, such as YouTube, blossomed due to a lack of interference from ISPs, or other corporate constraints. Thus

\footnotetext{
${ }^{6}$ The term "peer-to-peer" refers to the popular technology for file sharing; there are numerous software applications online that utilize this application to send files online.
} 
one must consider that throttling certain websites and applications could hinder innovation and development online. In relation to the common-carriage principle, slowing down a user's ability to access an application online is clearly in violation of what the Telecommunications Act (1993) was supposed to guarantee all users - open access without discrimination from carriers. As it will be further illustrated, since this first notable instance of traffic throttling, ISPs have continued to interfere with accessibility to websites because the Canadian government has not completely disallowed this practice of network interference.

Another instance in which the issue of network neutrality was brought before the CRTC is when Cybersurf, a Calgary based independent ISP, and other small ISPs filed a complaint in April 2008 against Bell Canada (CRTC, "Telecom Decision CRTC 2008117", 2008). These independent ISPs complained about over billing and anti-competitive behaviour, such as traffic throttling and Bell's unwillingness to provide wholesale ISPs with the same high connection speeds as Bell provides for its retail Internet subscribers (Chung, 2008). In November 2008, the CRTC ruled that Bell's throttling is not discriminatory, as the practice is also applied to Bell's own Internet customers (Chung, 2008). However, the ruling did not address the larger issue of whether throttling should be allowed or whether ISPs should avoid favouring some users or some applications over others, which is an issue linked to the network neutrality debate. After this ruling, the commission already had another proceeding in progress to study in more detail concerns regarding network management. In response to the CRTC ruling, the groups involved asserted the decision was flawed and would continue to interfere with the companies' 
ability to distinguish their service from Bell and thus contend effectively with larger ISPs in Canada such as Bell and Rogers (Geist 2008).

After this first ruling for Bell, the CRTC organized an extensive set of hearings, which took place in the middle of July 2009. These hearings allowed large ISPs to explain the kind of traffic management practices each corporation was utilizing, which will be revealed later in this essay. The CRTC's ruling came after considering, “...437 initial comments, 35 reply comments, and 34 final replies from parties (companies and advocacy groups) and individuals" with an online campaign resulting in over " 13,000 email submissions to the Commission from individuals." Also twenty-six presentations were heard at the July oral hearing, and the CRTC's online consultation resulted in 1,400 additional individual comments (CRTC, October 2009: para. 10),

On October $21^{\text {st }}, 2009$, after careful review, the CRTC announced its first major ruling on Internet traffic management practices in Canada, which is relevant to Internet neutrality concerns (despite the CRTC's avoidance of using the term 'Internet neutrality"); ISPs can still traffic throttle but it must be a "last resort." According to the CRTC, economic measures to improve their network's performance should be utilized by ISPs before traffic throttling (CRTC, "Telecom Regulatory Policy CRTC 2009-657”, 2009). For example, this implies that ISPs should continue to cap the amount of bandwidth users utilize, or charge subscribers additional fees for exceeding their monthly download limit. Also, included in the ruling, the CRTC will require ISPs to provide retail customers with thirty days notice of any changes to network management, and wholesale customers with sixty days notice (CRTC, "Telecom Regulatory Policy CRTC 2009-657",

\footnotetext{
${ }^{7}$ The CRTC to date has not yet defined the term network neutrality nor explicitly held a hearing on Internet neutrality in Canada. Internet traffic management practices are just one of the many issues surrounding the Internet neutrality debate, thus the hearing was not all encompassing of the term 'Internet neutrality.'
} 


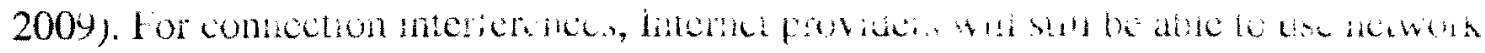
management practices, such as traffic shaping, and slowing of certain applications, and limiting bandwidth usage for heavy downloaders. However, the CRTC mandates that ISPs cannot target specific applications or else this practice would warrant further investigation. Traffic management is not a "free-for-all" and the ruling does require ISPS to fully disclose their practices. In addition, there are some restrictions for throttling, and traffic management is not the main recommendation as a way to deal with network congestion.

Thus, the CKTC hearing on Internet traffic management practices is relative to the Internet neutrality debate because the ruling does still allow ISPs to provide preferential treatment of certain applications and devices online. In order to truly understand how Internet traffic management practices were discussed at the CRTC hearing, and to illustrate the underlying values which motivate policy movements made by various stakeholders, the qualitative and quantitative research portion of this essay will examine the various positions of the speakers at the CRTC hearing regarding traffic management practices, such as targeting specific traffic online, including peer-to-peer file sharing. However, before delving deeper into the CRTC transcripts, it is important to explore the literature that has already been written on the subject of Internet neutrality, which will help illustrate the various perspectives and stances scholars have already taken on this issue.

\section{Literature Review}


Due to the increasing usage of the Internet as a medium for news and information, scholars are increasingly writing that Internet neutrality is a necessary and vital defence, which ensures that all online content remains equally accessible. Scholars from a diverse range of disciplines have begun to examine issues surrounding Internet neutrality, contributing viewpoints from areas such as communication studies, economics, technology, telecommunications law and policy, and also cultural studies. Interestingly, multifaceted sets of arguments have been provoked about the historical roots of Internet neutrality, the politics surrounding the issue, and policy implications of Internet neutrality, which varies in each country. In order to encapsulate the major developments in assessments of network neutrality, it is necessary to identify the discussions and debates in the literature.

As previously suggested, how scholars define Internet neutrality is not unanimous. For example, Wu provides a very simple definition of Internet neutrality as "an Internet that does not favour one application (say, the world wide web), over others (say, email)" (Wu, 2003). Significantly, Wu (2003) coined the expression "network neutrality" in his article, "Network Neutrality, Broadband Discrimination", where he makes the case for neutrally operated networks and service. Also, Gilroy builds on Wu's definition by suggesting that:

"...any such definition should include the general principles that owners of the networks that compose and provide access to the Internet should not control how users lawfully use that network; and should not be able to discriminate against content provider access to that network" (Gilroy, 2008).

Wu and Gilroy's definitions of Internet neutrality highlight the theme of non-preferential treatment of certain websites and applications over others; as the discourse analysis and 
content analysis will further illustrate, a non-discriminatory network was a key area of discussion in relation to the Internet traffic management hearing the CRTC held in July 2009. Thus their definitions demonstrate how Internet traffic management practice issues are quite similar to the concerns that Internet neutrality advocates have been writing about since 2003.

Furthermore, highlighting the importance of regulating control among Internet service providers (ISPs), Barratt and Shade (2007) classify Internet neutrality to consist of two key components, firstly that the Internet has no centralized control mechanisms, and secondly, those who own the networks do not control the content that runs over them. Barratt and Shade (2007) propose that the infrastructure of the Internet is "essentially just a large interconnected network of networks, which has no centralized control mechanisms", meaning that the Internet has been thriving because of its openness and ease of access. Keeping the Internet open and free from corporate constraints is a key concern of many Internet neutrality advocates, and these concerns were also discussed at the CRTC hearing on Internet traffic management practices being utilized by ISPs in Canada. As the primary research reveals, many of the speakers at the CRTC hearing opposed ITMP because they believed in maintaining an open Internet architecture. Unlike traditional mediums such as television, the Internet's lack of 'centralized control' has allowed the web to develop into an internationally utilized medium, which encourages its users to innovate with very few limitations.

Canadian legal scholar, Michael Geist, writes a highly consumed blog (www.michaelgeist.ca), which encourages the government to refrain from allowing ISPs the ability to control accessibility to content. Geist's blogs, which advocate for a non- 
biased Internet, suggest that if the Internet does not remain neutral, there is no protection from an inequitable telecommunications system. Another network neutrality activist who pays close attention to the Canadian Internet neutrality debate is Steve Anderson (2009); he presents network neutrality as a design to maintain a level playing field for online innovation and communication. Like Barratt and Shade, Anderson points to "common carriage" as the foundational basis for the current principles of Internet neutrality. Anderson also discusses the current situation in which ISPs in North America have already blocked or slowed down access to websites and content, limited bandwidth for applications, and have raised the prospect of charging extra fees for access to an exclusive Internet fast lane. His literature highlights that this battle for the Internet is between a handful of big telecommunication companies and online innovation, free speech, small business, independent media, artists, and civil society. While there are a handful of scholars who have examined the Canadian Internet neutrality debate, literature that pertains specifically to the Canadian situation, is still lacking in comparison to the amount of literature that has been written which examines the Internet neutrality debate in the United States.

Nonetheless, other academics that have examined the Internet neutrality debate, such as Sascha Meinrath and Victor Pickard (2008), also encourage governments to allow the Internet to remain an open source. However, pro net-neutrality academics, Meinrath and Pickard, suggest that:

"Much of the existing scholarship and commentary fails to sufficiently emphasize a central aspect of network neutrality, ignoring the import of normative principles - principles regarding the role of the Internet in a democratic society and the debt Internet providers owe to the public"(2008). 
In other words, they believe that the core idea of net neutrality is ensuring that the Internet remains open and participatory. Open access to diverse applications online is an Internet neutrality issue, which can be extended to the CRTC hearing on ITMP, because as the primary research will disclose, some of the stakeholders discussed their concerns regarding how alternative applications will be accessed by Canadian users if ISPs are allowed to target such applications. Also Meinrath and Pickard's work emphasizes that much of the research on the network neutrality debate overlooks exploring the idea that ISPs "owe" citizens the right to freely and openly access the Internet, without ISPs intervening or controlling traffic online.

The historical political economic perspective is apparent in Barratt and Shade (2007), Meinrath and Pickard (2008), and Anderson's (2009) literature; all these works suggest that private, corporate media conglomerates, and not public policy, increasingly control the Internet. This is the process of "re-regulation", according to political economist Mosco (1990). While it is more commonly identified as "de-regulation", it is "re-regulation" in actuality, since this process actually benefits large corporations, and involves less government involvement. This perspective is also important to consider because it raises questions regarding who has the authority to regulate the Internet, or should the Internet be "re-regulated"? In connection to this area of debate in Internet neutrality literature, the "re-regulation", or regulation debate also occurred at the CRTC hearing on ITMP. The ITMP hearing also examined whether ISPs should be allowed to self-regulate their networks, or whether the CRTC should propose guidelines on ITMP; thus studying the Internet neutrality debate through a political economic perspective is also relative to the CRTC hearing on network management practices. 
Another common assertion among net neutrality advocates, certainly one that Lawrence Lessig (2008) emphasizes, is that innovation will suffer if access does not remain open. Without net neutrality, applications and content innovators will be deprived of a way to demonstrate their new products to consumers, and subsequently, they may also be discouraged from innovating further. Although Lessig examines Internet neutrality from an American policy perspective, the notion that government policies from any nation that aims to regulate the Internet, “...require(s) political leadership - and public pressure to ensure that politicians aren't distracted by the telecom industry's cash and clout..." is still relevant to the Canadian dilemma of net neutrality (Lessig, 2008). Arguably, many scholars feel as though governments, such as Canada and the United States, should not allow ISPs more control over how their services are being utilized by subscribers. Lessig, as well as other pro-net neutrality academics, encourage governments not to allow ISPs to discriminate users based on the amount of money they are willing to pay to utilize the Internet. Preferential treatment of certain sites and applications is also an area of the Internet neutrality debate that will appear in the discussion of the primary research findings portion of this essay.

However, many scholars are not necessarily in agreement that the Internet must remain neutral, and that any sort of regulation is necessary to maintain net neutrality. Interestingly, in relation to concentration of ownership in the ISP market, scholars Hahn and Wallsten (2006) concern themselves with the way in which Internet neutrality can impact the market, and often address Internet users as consumers, instead of citizens. Hahn and Wallsten vouch for a "hands-off" tactic (another form of a neo-liberalism policy), and "deregulation." The authors contend that: "...mandating net neutrality would 
be inconsistent with sound economic management of the Internet" (Hahn and Wallsten 2006). Scholars Hass (2007), Globerman (2008), and Greenstein (2007), also concur that Internet neutrality would be undesirable for Internet consumers. These scholars have examined the debate from a market viewpoint; these academics tend to propose that any regulation will degrade the competence of the Internet, inhibit advancements, and limit prospective suppliers of financial support for potential communications expansion. Notably, and as it will be further exposed in the critical discourse analysis portion of this research paper, this is often reflected in arguments made by telecommunications companies, ISPs, and businesses.

Also opposing net neutrality are Lenard and Scheffman, (2006), who argue that innovation on the Internet would not be hindered without net neutrality. They suggest that, "...there is intense competition in local markets even with only two providers. A provider who denies access to content or applications that consumers find valuable will reduce the demand for its services" (Lenard and Scheffman, 2006). Accordingly, content that users want to access will continue to be available online, as long as consumers continue to visit these websites. ISPs do not benefit from losing customers, who are paying to use their services, which means that there is little incentive to impede the accessibility of websites that users are frequently visiting on the Internet. Interestingly, this concept was also used to defend ITMP at the CRTC hearing; many ISPs, like Lenard and Scheffman suggest, stated that their ITMP do not harm a user's ability to access content or applications online, because too many subscribers would become outraged. Furthermore, as the research findings on the transcripts reveals, it is evident that the CRTC hearing on ITMP is relative to the Internet neutrality debate as a whole, since ISPS 
at the hearing often used similar arguments that have been made by scholars who are opposed to network neutrality.

\section{Conclusions Regarding Literature in the Field}

In summary, the literature review has highlighted how scholars continue to question what a non-neutral Internet would mean for its users and its impact on their experience browsing the web, as well as what kind of regulation (if any) should occur online. Also, the Internet neutrality debate raises issues regarding the rights ISPs have over their services and whether ISPs should continue to manage traffic online if it results in the preferential treatment of certain sites and services at the expense of content providers who cannot afford to pay. Furthermore, it is evident that there are various definitions of Internet neutrality, and the way in which Internet neutrality is defined depends on the individual's background and understanding of the issue in relation to their own discipline.

As noted, some adversaries of Internet neutrality view regulation as a barrier to competition and improvements in technology, or unnecessary in terms of telecom policy.

Others who argue in favour of Internet neutrality often suggest that Internet traffic management practices go against the open architecture that the Internet was founded upon, which is noted by Barratt and Shade in their literature review. These perspectives tend to oppose government intervention, or believe that existing laws and policies can cover any potential problems on an individual basis (Globerman, 2008). There is a variety of opinions that arise in the Internet neutrality debate; while some scholars promote more government intervention to protect Internet neutrality, others want less or 
none to interfere with the infrastructure of the Internet. Most importantly, some scholars simply believe that Internet neutrality is not possible, and is not a policy that should be enforced, but those who want to ensure ISPs do not gain too much control over the future usage of broadband online heavily dispute this. The question of whether there is some sort of policy that can appease the demands of the public/consumers of the Internet, as well as the media conglomerates who own the pipelines of the Internet is an issue that commonly arises throughout the Internet neutrality debate.

Also, it is imperative to emphasize that many of the arguments made for and against Internet neutrality are relevant in relation to the CRTC hearing on Internet traffic management practices. For instance Wu was the first scholar to define Internet neutrality, and his definition explored the issue of certain applications and sites receiving preferential treatment over others. This concept of Internet neutrality is relatable to the discussion, which occurred during the CRTC hearing on ITMP, because some of the stakeholders, whose concerns at the hearing are discussed with more specifics in the primary research section of this essay, felt that network management practices such as throttling could be seen as ISPs interfering with the openness of the Internet. If applications are discriminated against, this creates an anti-competitive environment, since the ITMP utilized by ISPs are ultimately interfering with consumer accessibility online. Ultimately, the literature review provides an initial illustration of how the major themes of Internet neutrality debate, such as competition, discrimination, and innovation, are also themes that reflect some of the areas of concern the stakeholders addressed and discussed with the CRTC panel during the hearing. 
Finally, much of the pertinent research on Internet neutrality tends to theorize about its implications, since it is an area of debate which is still unfolding in Canada. Most of the texts analyzed in the literature review reflected a critical discourse analysis approach in order to understand the debate, and not much qualitative or quantitative data could be found in the literature review that directly relates to the Canadian context of network neutrality. However, the literature provides evidence that the academics that do advocate for Internet neutrality strongly suggest that if governments do regulate their Internet services (i.e. by means of policy measures), they place interests of the public and citizens before the demands of large media conglomerates. Whose interests are of most concern to the CRTC regarding the topic of traffic management in relation to the Internet neutrality debate, and what are the major themes of Internet neutrality are research questions that are explored in the primary research portion of this essay.

\section{Introduction to Primary Research}

As previously mentioned, the CRTC hearing on traffic management practices has transcripts available online on the CRTC's website; the transcripts document the responses towards various questions asked about Internet traffic management practices by the CRTC. These responses towards Internet traffic management practices were presented by twenty-six stakeholders at the seven-day hearing in front of a panel of CRTC commissioners. For the complete list of speakers (in order of appearance at the hearing) and commissioners at the CRTC hearing, please refer to Appendix A. The text of these transcripts is the primary source of data for the research portion of this essay. These texts were the subjects of a critical discourse analysis, as well as a content analysis 
to highlight themes, and arguments that were being made by ISPs, as well as academics and pro-network neutrality activists throughout the seven-day hearing. The critical discourse analysis and content analysis evaluates and identifies each presenter's response to the six key values that were selected by the researcher. Also the research methodologies connect and explore other themes that are relevant in relation to the term Internet neutrality, such as competition, and discrimination. The six values that have been selected and defined by the research for the content analysis portion of this research are also framed as values that can be associated with the Internet neutrality debate through a critical discourse analysis. A key issue associated with some of the values selected explores the issue of whether policy could protect Internet consumers from ISPs unjustly discriminating against certain applications and devices online, or whether enforcing protective measures online is even necessary. Through the utilization of these research methodologies, the transcending nature of Internet neutrality in Canada is explored, and the issue of why this topic needs more exploration in academia, since undeniably the Internet can be deemed a valuable resource and medium to many Canadians is further addressed.

\section{Content Analysis Framework}

It is important to expose the value perspectives that lie at the core of the deeply contested Internet neutrality debate, and to provide and understand the value differences among the speakers at the CRTC hearing in 2009. To achieve this, a content analysis aids in examining the values of each speaker at the CRTC hearing in July 2009 regarding Internet traffic management practices. The transcripts from the hearing are primary 
documents that provide raw data on the insights of various stakeholders who represented various interest groups and companies. While the hearing does not directly discuss the Internet neutrality debate in Canada, Internet traffic management practices utilized by ISPs are definitely viewed by most Internet neutrality advocates as an example of how the Internet could become non-neutral if ISPs can manage their broadband networks in anyway that they deem necessary. Also, it is important to note that the testimonies at the hearing reflect persuasive communication, which means that each presenter's statements at the hearing not only reflected the interests of the group (or views of the individuals), but also what they thought would persuade the commissioners at the hearing.

A content analysis allows for systematic examination of texts, and it is an effective research method for studying attitudes, beliefs, values, and human relations (Woodrum, 1984). Also, the methodology is unobtrusive, and can aid in presenting themes and patterns in lengthy texts, like the transcripts being used for this study. The following content analysis provides considerable insight and research on the values on Internet traffic management practices in Canada, and follows a similar system of codification as a conference paper entitled: "Values of Stakeholders in the Net Neutrality Debate: Applying Content Analysis to Telecommunications Policy", which was presented at the 43rd Hawaii International Conference on System Sciences by Cheng, Fleischmann, Wang, Ishita, and Oard, from the University of Maryland, and Surugadai University. The report provides a quantitative study that illustrated the top values implicated in the network neutrality debate in America, and its analysis reveals "insights into the connection between specific values and positions on the Net neutrality debate" 
(Cheng et al, 2010). Firstly, the researchers define what they mean by "values", a term classified by Schwartz' work; their report suggests:

"Values serve not only as determiners of choices, but also as foundations for attitudes towards personal needs and societal demands. Values influence both individual choices and societal policy directions. Analysis of values within ongoing policy debates can predict and explain individual and societal choices" (Cheng et al, 2010).

This concept and definition of "values", as proposed by Schwartz' work, is applied to the content analysis on the CRTC hearing on Internet traffic management practices in this research report. It is interesting to consider how Schwartz' Value Inventory, which is a list of 56 basic human values that was validated through cross-cultural survey research, can be applied to a policy debate, such as Internet traffic management practices (Schwartz, 1992).

Furthermore, the Internet traffic management practices debate is an issue which is also relative to the Internet neutrality debate in Canada. Thus, as scholars, Cheng, Fleischmann, Wang, Ishita, and Oard suggest, "Values [can] influence policy goals, decisions, and implementation. At the same time, policy analysis also influences the values of participants in the policy-making process and of people affected by this process" (2010). The purpose of selecting six of Schwartz' values as a means to organizing a content analysis is that it can be used to codify the differences and similarities in value judgements amongst each stakeholder group. While this content analysis uses a similar coding framework as Cheng's et al. (2010) content analysis, there are some variations in how certain values were selected and applied to the CRTC hearing in contrast to the ones utilized in the paper,"Values of Stakeholders in the Net Neutrality Debate: Applying Content Analysis to Telecommunications Policy." For example, 
instead of counting the frequencies of all of Schwartz' values, this research analysis selected six of the values utilized in the conference paper and recorded how each value was perceived by each speaker at the hearings after closely reading each speaker's presentation at the hearing. Also, instead of counting the frequencies of Schwartz' values, this content analysis is more qualitative in nature, because it notes whether each of the six values were regarded as a positive, neutral, or negative by the representative/speaker at the CRTC hearing on Internet traffic management practices. How positive, neutral and negative is defined by the researcher can also be found in Appendix A of this research paper. Also, the research includes a calculation of the total average attitude of each value by including the total mean, median and mode of each of the six values' evaluations, as well as individual daily mean, median and mode calculations of each value. This calculation will assess what the general response and daily response of each value was during the seven-day hearing.

Coding the stakeholders' stances towards the six values as positive, neutral, or negative, ultimately aids in explaining how each of the six values influences and motivates each representative's stance on Internet traffic management practices, which came to light during the seven-day hearing. Thus this content analysis assesses each representative who spoke at the hearing's attitude towards the six different values that have been selected which are: 1) wealth, 2) freedom, 3) capable, 4) influential, 5) equality, and 6) authority. Definitions and explanations of how each value was coded can be found in Appendix A. These six values were selected after examining the results from Cheng's content analysis on the American Net Neutrality hearing; however Cheng's conference paper includes explanations of the ten most frequent values counted during 
the American network neutrality hearing and this research only uses six. For the purpose of this analysis, six of the top ten values from Cheng's paper were applied to the CRTC transcripts on Internet traffic practices because they were deemed by the researcher to be most evident and applicable to the themes of the discussions at the hearing after a preliminary read through of the transcripts.

Also, another content analysis was conducted with two research questions in mind: does congestion actually exist online, and is peer-to-peer sharing a main source of congestion for ISPs? Since the issue of congestion was briefly introduced in the previous sections, it is important to emphasize that network congestion is a key concern of ISPs in Canada. ITMP are often justified by ISPs in Canada as a means to combat traffic congestion, because ISPs assume that the amount of bandwidth that Internet users are utilizing online is constantly increasing. Also, many ISPs (as well as many of the individuals on the CRTC panel $^{8}$ ) deem peer-to-peer sharing applications as a main source of congestion. ISPs argue that congestion harms a user's online experience, and must be managed through the utilization of ITMP; however, there was some evidence at the CRTC hearing that congestion is not an actuality, and its existence is disputable. Thus the issue of congestion becomes an important topic to connect to the Internet neutrality debate since it brings up the issue of whether regulation could aid in managing online traffic congestion. Regulation is a key issue in the literature regarding the Internet neutrality debate, and is relatable to the issue of managing congestion online.

This smaller content analysis frames what the stakeholders' stances were towards this question, and were coded with a response of either yes, no, or no opinion.

\footnotetext{
${ }^{8}$ After the first day of the ITMP hearing, it became evident that the CRTC panel already assumed and agreed that online congestion was an issue - no one on the panel questioned if congestion was an actuality, and asked questions which focused cn how ITMP should be utilized to manage traffic congestion instead.
} 
Furthermore, a third content analysis counted the frequencies of three words: congestion, discrimination/discriminatory, and competition/competitive; it was pre-supposed by the researcher that these three words would come up quite frequently throughout the hearing. The frequency of each word's use daily and in total throughout the entire hearing was included as part of this content analysis. Now that all three of the content analyses have been introduced, the results of all three content analysis will now be discussed and revealed.

\section{Values of Stakeholders at the CRTC Hearing - Content Analysis 1}

\section{Variable 1 - Wealth}

Since the initial content analysis examined six values, it is interesting to compare the similarities and differences in opinions amongst the twenty-six speakers who presented in front of a CRTC panel of commissioners. The first value that was examined was wealth; wealth is the value that examines the issue of whether profitability is a concern or issue for the speaker at the CRTC hearing. Of the twenty-six speakers, eighteen of the stakeholders' presentations suggested to the researcher that it is important to ensure that the Internet is profitable; however there are differences in the way in which each stakeholder will profit from Canadians browsing the Internet. Also, depending on how the speaker felt about the current Internet traffic management practices, there were differences amongst the various speakers at the hearing regarding the issue of how the Internet could be the most profitable to their own businesses or interests. Please refer to Appendix A, Figure A for a complete chart of how each stakeholder responded to this value. 
For instance, stakeholders at the hearing, such as large ISP owners like Bell and Rogers, emphasized that utilizing Internet traffic management practices, is a method to ensure that their customers are receiving the best service possible from their subscription. If a customer is happy with their services, the customer will likely stay a loyal customer for a lengthy period of time. ISPs mainly argued at the hearing that they use Internet traffic management practices as a means to control their supply of broadband to keep up with the increasing demands of their customers; if ISPs cannot do so, and receive complaints, this means less profitability.

On the other hand, there were speakers at the hearing, such as Zip.ca, who were concerned about profitability of the Internet because thus far, utilizing the Internet had not been very profitable for their company. Zip.ca spoke on the second day of the hearing and made a remarkable revelation in front of the CRTC panel. Interestingly, Zip.ca suggested that it is cheaper to spend money on postage to send DVDs via mail, rather than distributing the same content online, because of the high expense of bandwidth (CRTC, "Volume 2", 2009). Also the issue of applications not being able to be as quickly accessed online as others became an issue of profitability and wealth throughout Zip.ca's presentation. Due to the fact Internet traffic management practices allows preferential access to certain websites and applications over others, smaller companies, like Zip.ca will be at a disadvantage if the application they are utilizing is not favoured by an ISP like Bell.

Since Bell has such a large share of the broadband in Canada, and is increasingly re-purposing offline content such as television or radio shows, for online distribution, this puts companies who wish to stream their own content at a disadvantage. Zip.ca's 
presentation explains that, "If their internet traffic is exempt from any rules you set on network neutrality, your application level filtering, then basically they are allowed to say that their application goes through with priority and mine doesn't, and that certainly would be an issue to us" (CRTC, "Volume 2", 2009: 1413). Thus Internet traffic management practices did raise questions and issues regarding how each stakeholder was concerned about the future profitability of the Internet, and wealth was definitely an important value, and was deemed positive by the majority of stakeholders that spoke during the hearing. The discourse analysis portion of this research further explores how valuing wealth is often an argument used to dispute Internet neutrality. Wealth was definitely viewed as positive and important dimension of utilizing the Internet; the potential for increasing one's wealth by utilizing the Internet undeniably encourages online innovation and advancements in technology.

\section{Variable 2- Freedom}

The second value that was explored was freedom, which is the value that investigates the ability for an individual or company to make their own choices, and express their own ideas on the Internet. This value was framed in the following research question: is it important for Internet users to have individual freedoms online? Throughout the seven-day hearing, many of the speakers expressed the importance of keeping the Internet open and allowing each user the freedom to access any content or applications they want online. From the perspective of speakers who represented a more pro-Internet neutrality stance at the hearing, freedom was a value that was regarded as very important and a very positive value for Canadian Internet consumers. For the 
complete codification of each stakeholder at the hearing, please refer to Appendix A, Figure D.

The stakeholders who tended to favour the value of freedom more positively were smaller companies, or independent producers of content. For example, one of the stakeholders who have been rated positively by the research is the Independent Film and Television Association (IFTA). Their presentation in front of the panel on day three of the hearing emphasized the importance for Canadians to freely access content available online. The issue of utilizing Internet traffic management practices raises concerns that: "...the ISP gatekeepers will grant the same preferential treatment and carriage to ISP owned and/or affiliated content and squeeze out independent producers from the last open and democratic distribution platform under the guise of network management." (CRTC, "Volume 3", 2009: 2073). This statement at the hearing illustrates one of the key concerns regarding Internet neutrality and concentration of media ownership - the inability to freely access diverse sources. Those who tended to favour CRTC regulation of Internet traffic management practices also tended to favour consumer rights and freedoms online. As the statement from the IFTA illustrates, those who spoke at the hearing that agreed with Internet regulation had a tendency to use the value of freedom as an argument to support such policy measures; regulation could be used to protect consumer freedoms and rights online.

ISPs like Bell and Rogers did not express a positive rating for this value. While Rogers did suggest that they are not providing preferential treatment of their own content services over other websites, their Internet traffic management practices do target peer-topeer file sharing applications such as BitTorrent. Since BitTorrent, as IFTA and other 
stakeholders at the hearing suggested, is used commonly amongst independent content producers to share files, targeting this sort of application can be perceived as a negative response towards freedom online. Other ISPs such as Cogeco and Telus reflected a negative attitude towards the value of freedom as well. Major ISPs proposed at the CRTC hearing, that some online freedoms, such as downloading BitTorrents, need to be restricted and regulated by ISPs themselves to ensure that all their customers are not experiencing the effects of online traffic congestion. For example, on the seventh day of the hearing, Bell's speaker suggested that CRTC regulation of Internet traffic management practices would actually hinder, not maintain online innovation. Since innovation is a word that is closely linked to the arguments made in favour for online freedoms, it is interesting that ISPs like Bell would use the value of freedom as a means to justify Internet traffic management practices; this seems paradoxical in nature since as suggested Internet traffic management practices could stifle innovation if it targets independent producers and distributors. Bell went on to suggest that:

"Where some see the need to impose regulatory rules to protect application innovation, we see their demands as seeking regulatory rules that would limit, or even ban, innovation at the network level. Quite simply, imposing ex ante rules that limit or ban innovation at any layer is by definition a greater threat to innovation than having no ex ante rules at all" (CRTC, "Volume 7", 2009:5978).

Thus opponents of Internet neutrality also invoke the value freedom as validation of their current Internet traffic management practices; Bell and Rogers are key examples of ISPs that downplay the extent to which differentiation among users is a hindrance to consumer choice. While it was not surprising that ISPs did not value freedom in a positive regard, it was surprising that ISPs used the value of freedom as an instrument to argue their side of the debate. The majority of the speakers at the seven-day hearing valued the Internet as a 
medium that allows Canadians to access diverse content and sources, and innovate and create new ideas at a national and international scale.

\section{Variable 3 - Capable}

Capable was the third value that was defined and coded. Capable can be defined as the value or potential of doing something effectively, and was framed in the research question of whether policy is capable of ensuring Internet traffic management practices are non-discriminatory, or whether policy is even necessary to regulate the Internet. Interestingly, of the twenty-six stakeholders who spoke at the hearing, thirteen of the speakers viewed this value as positive, but there were also ten stakeholders who suggested that the CRTC was not capable of regulating the Internet. This means that there was almost an even divide amongst the twenty-six stakeholders whether the CRTC was capable of using policy to regulate Internet traffic management practices. As figure I illustrates in Appendix A, the fifth and the seventh day of the hearing had a mean average of a negative representation of the capable value research question. On these days, Bell, Rogers, and other main ISP providers in Canada spoke in front of the CRTC panel, which illustrates that ISPs are against regulating the Internet through policy measures. On the other hand, the second and third day of the hearing presented the most stakeholders with positive attitudes towards the CRTC's capability of regulating Internet traffic management practices. The speakers on these days were mainly, consumer interest groups and smaller companies.

For example, the Alliance of Canadian Cinema, Television and Radio Artists (ACTRA) presented an argument that illustrates a positive response towards the CRTC 
regulating the Internet on the third day. The ACTRA strongly presented the opinion that the CRTC should interject with how Internet traffic management practices are being utilized, and notes that: "We know ISPs are already using traffic management practices. The Commission must make it clear that this is not a long-term solution and regulate the practice..."(CRTC, "Volume 3", 2009: 2520). The ACTRA, as well as other stakeholders who argued in favour of CRTC regulation, proposed a variety of guidelines for the CRTC to abide by to ensure that ISPs are not granted too much freedom to self-regulate their own broadband networks. One guideline that was commonly suggested by those who viewed this value positively, like the ACTRA was that, “...the onus should be on ISPs to prove they need to manage traffic in order to manage the integrity of the system" (CRTC, "Volume 3", 2009: 2521). As the second content analysis illustrates, many stakeholders at the hearing questioned the reality of how badly ISP networks were congested, and if congestion even existed online. Due to the fact that ISPs generally have not provided much evidence prior to the hearing (or even during the hearing) that congestion truly exists, those who are opposed to Internet traffic management practices generally questioned if this sort of congestion is an actuality, and wanted the CRTC to force ISPs to prove Internet traffic management practices were even required to ensure a more favourable experience for a Canadian Internet consumer.

Nonetheless, it is interesting to assess the other side of the debate; these are the stakeholders, mainly ISPs, who did not view policy as a favourable method to regulate Internet traffic management practices. ISP provider, Shaw Telecommunications, was one of the many stakeholders who discouraged the CRTC from regulating Internet traffic management practices, and suggested that, "Because there is no one-size-fits-all 
approach, the Commission must allow each ISP to select the network management practices that are best suited for their particular network" (CRTC, "Volume 6", 2009: 5623). Similarly, ISPs such as, Cogeco, Bell and Rogers also shared a similar viewpoint towards whether or not the CRTC was capable of regulating the Internet. These ISPs want the ability to self-regulate without CRTC interference; during the hearing, these ISPs did not see any issues with the way in which they were utilizing Internet traffic management practices.

Capable was a value that was argued in both a positive and negative perspective by stakeholders at the CRTC hearing and it was one of the main concerns for stakeholders regarding regulating the Internet. Those who did not deem regulation as possible or capable of ensuring a fair and neutral network argued that if all purchasers faced a uniform access price, without regard to usage, the common resource would be allocated inefficiently. On the other hand, those who deemed the capability of regulation as a positive suggested that it is important that the CRTC regulates the methods of Internet management practices, to ensure innovation is not stifled, and ISPs are not using discriminatory forms of management on their networks. Basically there was almost an even divide amongst stakeholders at the hearing in regard to whether or not the CRTC was capable of regulation; for the complete coding of this value please refer to Appendix A, Variable 3.

\section{Variable 4 - Influential}

The forth value, influential, was also coded in a similar manner as the first three variables. The variable influential, or influence, is the value that explores the impact of 
actions; in this research, influence was framed in the research question of whether the current Internet traffic management practices were influencing Canadian Internet users in a positive or negative manner. The mean average response to this question during the hearing was again almost evenly split by the twenty-six presenters; sixteen stakeholders at the hearing deemed the current Internet traffic management practices to be having a negative influence on Internet user's experiences browsing online, and ten of the stakeholders viewed Internet traffic management practices as a positive influence. Again, the stakeholders were not united, and almost equally divided on this issue during the hearing.

Service providers, and anti-net neutrality stakeholders at the hearing put significant emphasis on the value of influential. Sandvine is one example of a stakeholder who argued in favour of Internet traffic management practice's influence on the first day of the CRTC hearing. Sandvine presented that, “...there have been a very limited number of complaints and even lesser number of violations alleging unjust traffic management practices in Canadian Internet. Is anything broken? Is there compelling real-world evidence of the need for new guidelines?"(CRTC, "Volume 1", 2009: 88). The main argument that many ISPs made during the hearing was that they had received little to no complaints about the Internet traffic management practices they were utilizing. However, as opponents of Internet traffic management practices also proposed at the hearing, many Canadians are simply not aware of how their network is being managed by ISPs, or that Internet traffic management practices even occur. As the critical discourse analysis emphasizes, a lack of awareness amongst Canadian Internet consumers is a critical issue. Other stakeholders who viewed Internet traffic management practices as favourable also 
suggested that Internet traffic management practices were having a positive influence on Canadian Internet users because these practices are utilized to ensure every subscriber has quick and timely access to websites and applications online. In the case of time-sensitive applications, such as Voice over IP, or VOIP, traffic management practices can aid in ensuring that there is no "lagging" in how quickly messages are received by the other user they are trying to connect with online. On the first day of the hearing, Juniper Networks explained various Internet traffic management methods that are commonly utilized online and suggested what applications need to be accessed quickly have changed over time. For example Napster was an application that used to be accessed by Internet users to download music, but due to numerous copyright issues, it was shut down. Thus, Internet users who want to download music online no longer use Napster. Juniper suggests that: "...if we look at the kinds of applications that occur on the network today versus if we look back 15 years ago the majority of the Internet was simply a little bit of Web, and mostly file transfer, and some e-mail. The types of applications that we leverage today are fundamentally different than how we built these networks originally" (CRTC, "Volume 1", 2009: 417). Essentially, because the way in which the vast majority of Canadians are utilizing the Internet is constantly changing and developing overtime, ISP traffic management practices are always adapting to these changes. Currently, these stakeholders in favour of Internet traffic management practices suppose that is not reasonable to leave a network unmanaged if there are so many time-sensitive applications being utilized on the Internet, such as online gaming, or using instant messaging applications. 
In contrast, those who argued that the current Internet traffic management practices are having a negative influence on Canadian Internet users at the CRTC hearing often suggested that Internet traffic management practices impacts a user's ability to access content produced by independent producers. On the second day of the hearing, the Open Internet Coalition suggested that, “...practices that undermine the Internet's openness are bad for innovation; in this case, application-specific traffic management practices. ITMPs that discriminate between applications distort market forces and harm user choice" (CRTC, "Volume 2", 2009: 1016). Also as noted earlier, stakeholders who did not favour the influence of Internet traffic management practices, argued for more transparency of these practices from ISPs. For instance, on the third day the Council of Canadians with Disabilities and ARCH Disability Law Centre presented a different viewpoint of how Internet traffic management practices could have an impact on Canadian users with special needs. Their concerns were that if traffic management practices target specific applications, this could mean that applications that Canadians with disabilities utilize could also be targeted. ARCH's presentation reminded the committee that, "Unfortunately, some of these services and applications may look like, or be taken for non-traditional applications or services that the ISPs are concerned about, for example P2P" and, "Even when they don't look like programs that the ISPs are concerned about, these accessibility-related applications may be degraded simply because they are not recognized applications..." (CRTC, "Volume 3", 2009: 2312). It is important to keep in mind that people with disabilities also rely on the Internet to improve their quality of life, and traffic management practices are currently having a negative influence on these individuals. 
However, MTS Allstream, who spoke on the third day of the hearing, is an example of a stakeholder who viewed the influence of Internet traffic management practices in a very different manner than other stakeholders who were also coded as viewing this value negatively. Their presentation did not concern itself with retail Internet traffic management practices, but was more interested in the use of these methods on wholesale Internet customers. At the hearing, MTS Allstream argued that, "Dominant carriers can and should be required to manage their own retail Internet traffic separately from that of their wholesale access customers" (CRTC, "Volume 3", 2009: 2632). Since ISPs such as Bell and Rogers also use Internet traffic management practices on their wholesale customers as well as retail subscribers, this raises the issue of wholesale providers not being able to compete with the six largest ISP providers in Canada. Internet traffic management practices, which extend to wholesale providers, means that wholesale providers cannot differentiate their services from these media conglomerates. To conclude, the influence of Internet traffic management practices as both a positive or negative measure was heavily debated amongst the stakeholders at the hearing, and its influence was argued on both sides of the debate.

\section{Variable 5 - Equality}

The fifth value examined was equality, which was also coded as the previous variables. Equality refers to the ability to have the same status, rights, and opportunities as others. Equality is valued in this content analysis to examine whether network players and consumers have the same rights and opportunities as one another. For example, do independent content producers have the same opportunities to be accessed online as 
content distributed by larger network players? The mean average response to this value was either neutral or negative; however fifteen of the stakeholders regarded this value as negative, eight viewed it as neutral, and three stakeholders felt it was positive, meaning that the stakeholder felt that consumers and network players had equal opportunities and rights online. The results of the research have calculated that the majority of stakeholders felt that current Internet traffic management practices had a negative effect on this value.

While some of the stakeholders did fall under the neutral codification in this analysis, more attention will be directed towards the arguments made by stakeholders who were given a negative codification in Figure $\mathrm{N}$ of Appendix $\mathrm{A}$. The Canadian Association of Internet Providers (CAIP), and the Canadian Internet Policy and Public Interest Clinic (CIPPIC) are two examples of speakers who suggested Internet traffic management practices created inequities between ISPs and their customers. CAIP argued that it was competition, not congestion that is at issue; like MTS Allstream, CAIP strongly urged the CRTC panel to not allow ISPs to use traffic management practices on wholesale customers. CAIP noted how little competition exists amongst ISPs and smaller wholesale providers:

"...the Commission's own Communications Monitoring Report reveals, dominant carriers have an overwhelming market share of retail internet access, accounting for 88 percent of the total revenue market share for internet access service, and 95.5 percent of residential subscribers in 2007" (CRTC, "Volume 4", 2009: 2967).

Again, the issue of wholesale providers being unable to differentiate their services from larger ISPs illustrates how unequal the playing field is for smaller ISPs in Canada. The CIPPIC reminded the CRTC panel that ISPs could easily have an advantage over smaller distributors who utilize applications that are targeted by Internet traffic management 
practices, such as BitTorrent; there is the potential for their own distribution services receive priority over their competitors online. Steve Anderson, who was referred to in the literature review portion of this essay, stated that Internet traffic management practices, “...sets up incentives for ISPs to confer undue preferences on their own distribution services, especially with respect to wholesale customers. This is a very problematic but difficult issue to monitor" (CRTC, "Volume 4", 2009: 3393). Discrimination of specific content and applications online was a key concern of numerous stakeholders throughout the hearing; also ensuring equal competition amongst service providers was another argument that was relative to the equality value.

On the contrary, service providers, not unexpectedly, view equality differently from those who were against current Internet traffic management practices. Large service providers such as Cogeco, Telus, Bell or Rogers argue that discrimination does not exist in the reality of competition between service providers. Telus denied any preferential treatment of any associated dealings, and stated that:

“...we understand why non-affiliated providers of content worry about undue preference. Luckily, we already have robust non-discrimination rules in Canada, the very rules that net neutrality advocates in the U.S. continue to seek. That to us is a critical point of departure from the net neutrality debate that is raging south of the border"(CRTC, "Volume 5", 2009: 4083).

It is particularly interesting that Telus referred to the Internet neutrality debate in the United States; during this hearing the United States had yet to issue Internet neutrality regulations, but since the CRTC hearing on Internet neutrality, the Federal Communications Commission (FCC) has decided to issue Internet neutrality guidelines. Also, as already mentioned, the CRTC panel was careful not to refer to the hearing as an 
Internet neutrality debate. Regardless, the opponents of regulating network practices have a very different and contrasting opinion on equality.

\section{Variable 6 - Authority}

The final variable analyzed in this content analysis was authority; this value evaluates whether the stakeholders at the hearing deemed the CRTC to have the power to regulate Internet traffic management practices utilized by ISPs. Interestingly, the mean average response to this value was almost evenly divided between being coded as positive or negative; for the complete chart of how each stakeholder was coded please refer to Appendix A, Figure Q. Of the twenty-six speakers at the hearing, fourteen presenters felt that the CRTC had the authority to regulate traffic management practices, eleven stakeholders argued otherwise, and one stakeholder was coded as neutral.

Negative responses to this value often made the argument that the success of the Internet is because the government has been not intervening and creating new policies to regulate networks. On the fifth day of the hearing, Rogers' suggested that: "Canada has the highest penetration of cable modem service in the world and the highest penetration of broadband in the G8 countries. All of this has been accomplished with the minimum of government regulation. Market forces, not government fiat, are responsible for Canada's remarkable success" (CRTC, "Volume 5", 2009: 4901). Also, Cogeco is an ISP that approves of this hands-off approach, and their presentation concluded that, "...no regulatory measures designed to regulate ITM practices are required at this time"(Day CRTC, "Volume 5", 2009: 4469). ISPs want the CRTC to demonstrate restraint in exercising their authority, and often argue that because the way in which networks are 
being utilized is constantly changing, regulation could quickly become outdated and too restrictive.

However, stakeholders who deemed the CRTC to have enough authority to regulate Internet traffic management practices want the CRTC to use their authority to amplify competition and defend consumer rights. One key consumer right that was a frequent issue was privacy; many stakeholders who were opposed to Internet traffic management practices had concerns regarding how much information was being exposed and stored because of the use of Deep Packet Inspections (DPI). ISPs use DPI as a means to target kinds of traffic they want to slow down; for example the slowing down the download speed of peer-to-peer file sharing is one way DPI is utilized online. Stakeholders who viewed the authority of the CRTC as positive wanted more intervention from the government to ensure ISP traffic-management practices are regulated to protect a variety of consumer rights, like privacy.

\section{Conclusions of Content Analysis 1}

The six key values that were examined by the first content analysis highlighted a variety of themes of the arguments made by those who were for regulating Internet traffic management practices, and those who are against the CRTC intervening with network regulation. The first value examined (Figure 1), wealth, highlighted the perspectives of why the future profitability of the Internet was a concern to each stakeholder. Each stakeholder who spoke at the CRTC hearing shared similarities and differences in their evaluation of how Internet traffic management practices could impact their company, or interest group. Nonetheless, the vast majority of the stakeholders valued the importance 
of wealth in a positive manner, which further emphasizes how the Internet has become an important medium to develop and share innovations and ideas for a variety of Canadian businesses and consumers.

Figure 1

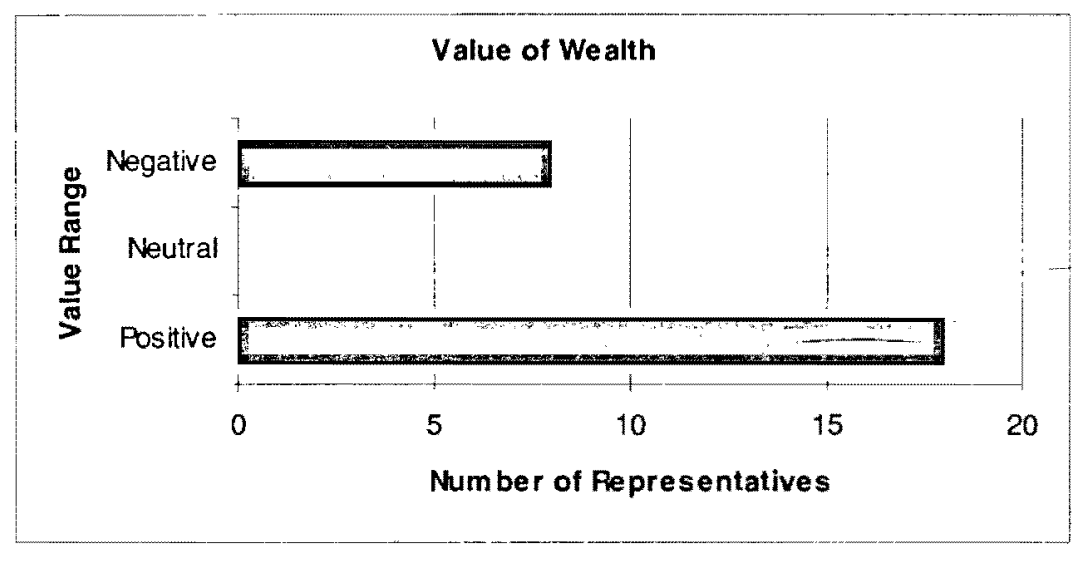

Secondly, freedom was a value that was argued both ways throughout the sevenday hearing (Figure 2). Consumer freedoms are arguably discriminated against with the usage of Internet traffic management practices; a number of Canadian Internet subscribers are likely unaware of why certain applications and services online load slower than others. Public awareness of the problems associated with Internet traffic management practices is definitely lacking; individual freedoms online are a key area of concern for numerous stakeholders who spoke at the hearing. Also, the value capable (Figure 3), explored the question of whether or not it was possible for the CRTC to regulate Internet traffic management practices. Stakeholders were very divided on this 
issue; while some presentations put forth that it would be difficult to regulate the Internet because it is a medium that constantly changes in its usage, other stakeholders emphasized that the CRTC was capable of ensuring consumer rights were being protected. Many of the presenters who argued in favour of the CRTC's capability to regulate wanted a policy that ensured that ISPs did not use certain traffic management practices which would discriminate against applications like BitTorrent.

Figure 2

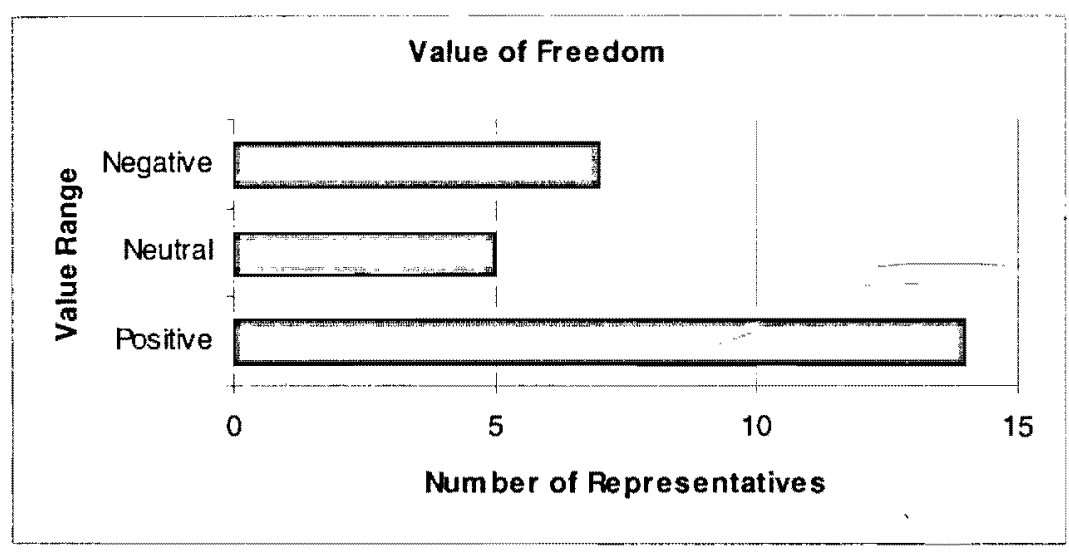

Figure 3

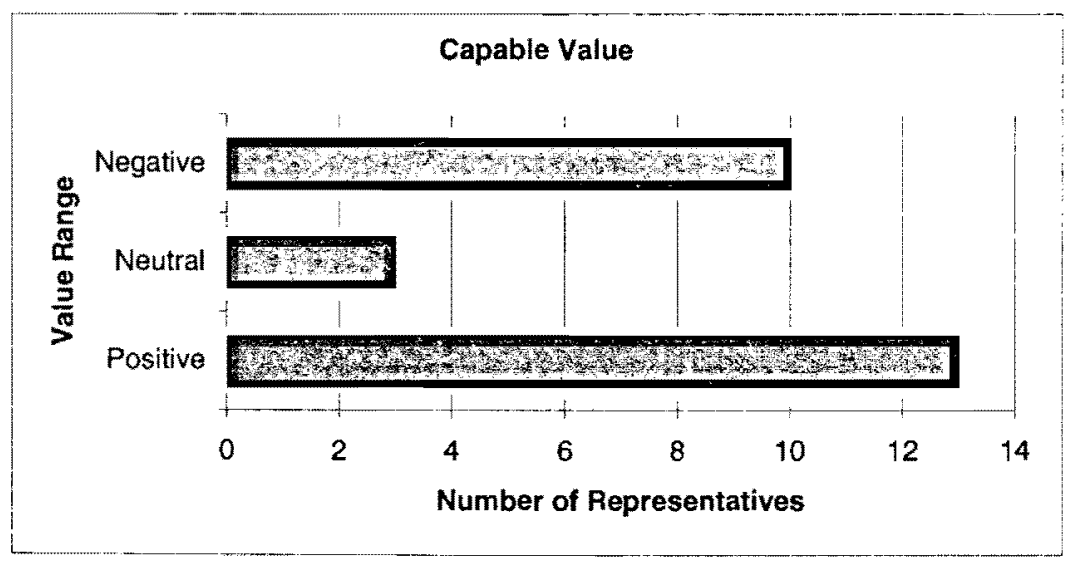


In addition, the value of influence (Figure 4) examined whether current Internet traffic management practices had a negative or positive effect on Canadian subscribers and users. Most stakeholders seemed to agree that some traffic management practices, such as the ones that stop viruses and spam online from spreading, were acceptable; however, the stakeholders were divided on how other traffic management practices were impacting Canadian users. Finally, equality (Figure 5) and authority (Figure 6) were two important values and themes that arose during the hearing. Wholesale ISP providers argued that ISPs should not use Internet traffic management practices on their networks because the amount of people who subscribe to their services is much smaller in scale than large ISPs such as Bell and Rogers, meaning that there is less congestion on their networks so traffic management practices are likely unnecessary. The stakeholders were also divided on the issue of whether or not the CRTC had the authority to regulate Internet traffic management practices. The main question surrounding this value was whether regulation was even necessary, and if the CRTC had enough evidence to intervene and change the way in which ISPs are using traffic management practices. Furthermore, the major themes and findings from this content analysis will later be connected to the discourse analysis on the CRTC hearing.

Figure 4 


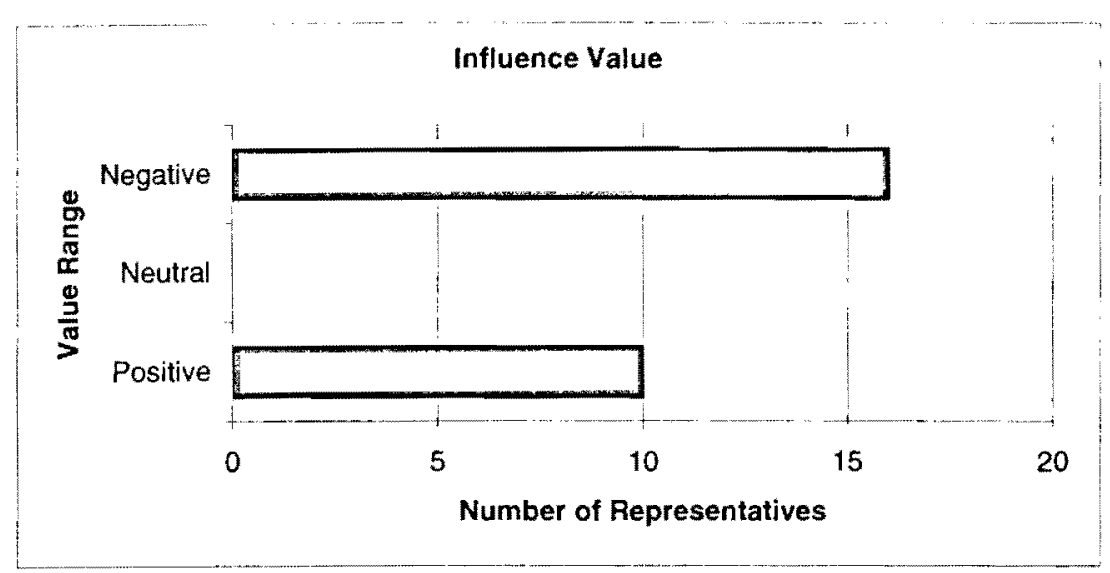

Figure 5

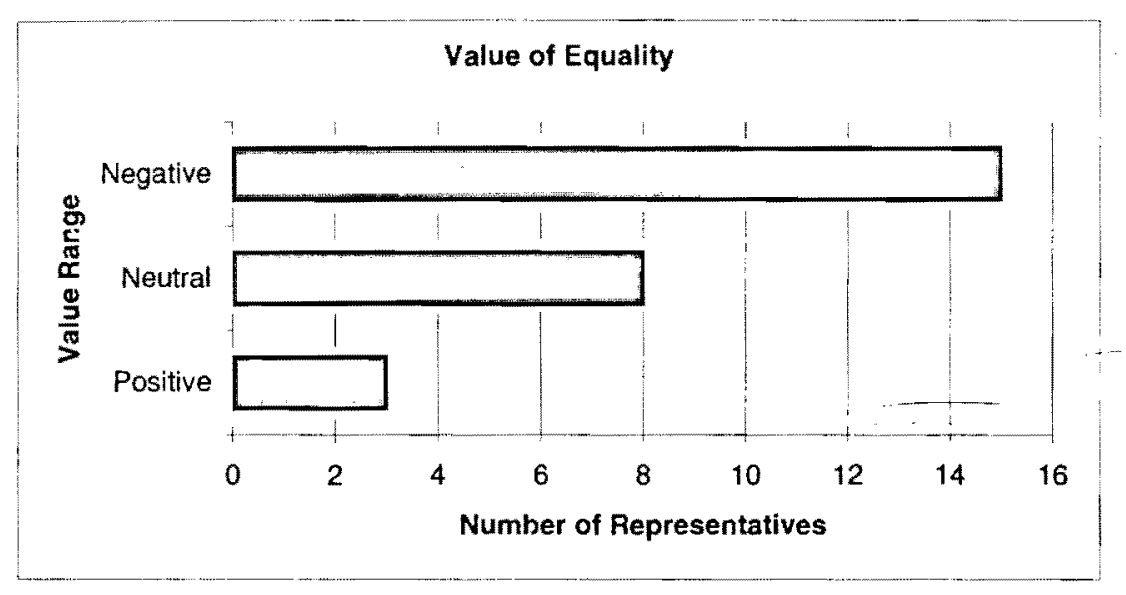

Figure 6

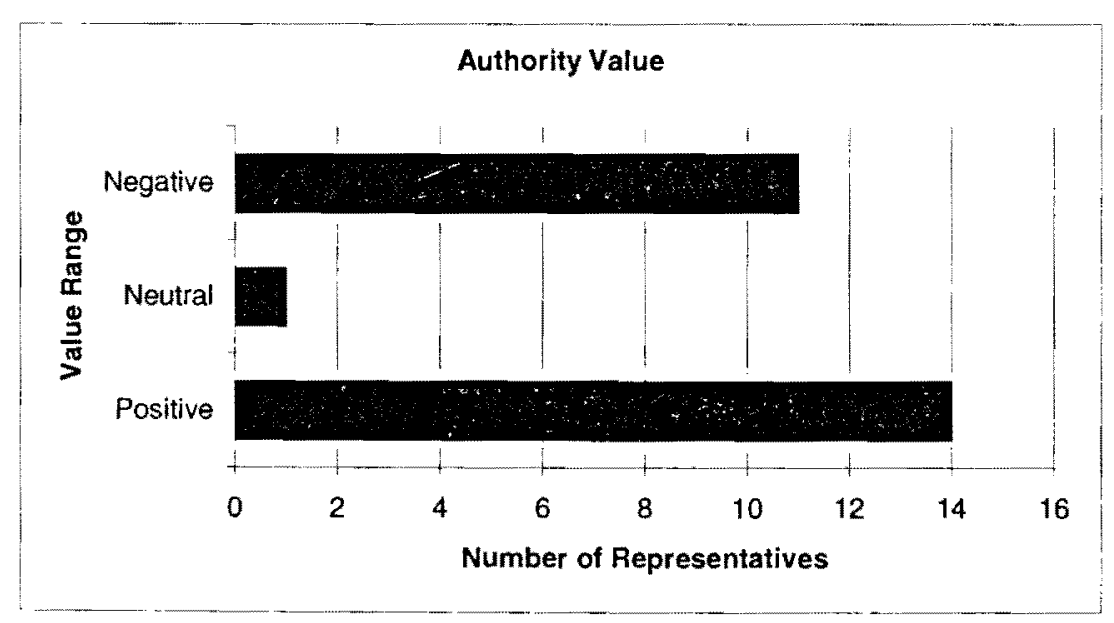




\section{Key Research Questions and Consistency of Terms Selected - Content Analysis 2 and 3}

The following content analysis assesses key questions that were addressed during the CRTC hearing on Internet traffic management practices. Each actor's response to the issue in question has been coded either: yes, no, or no opinion; for complete definitions and explanations of the codification of the two research questions, please refer to Appendix B. The first question that examined whether the stakeholders believed congestion actually existed online, and the second question examined whether each speaker at the hearing believed peer-to-peer sharing applications (such as BitTorrents), are a main source of congestion for ISP networks. The second content analysis counted the frequency of the words: competition/competitive, congestion, and discrimination/discriminatory throughout the seven-day hearing; Appendix $\mathrm{C}$ includes charts and graphs of each value, to illustrate its daily and total frequency throughout the hearing. While the third content analysis is the least in-depth study of the three, it is still interesting to examine how often both the stakeholders and the CRTC panel utilized these three terms in conversation, during the hearing. A word counting program, as well as manual counting, was employed to record each word frequency.

To begin with, the second content analysis was a follow-up to some of the research questions that were excluded from the first content analysis, which assessed six values amongst stakeholders. Before the hearing began, it seemed as though the CRTC panel had already made the assumption that traffic congestion exists online. However, numerous stakeholders questioned if this was an actuality, or a problem that has been fabricated by ISPs to justify the usage of Internet traffic management practices. Fifteen, 
of the twenty-six stakeholders at the hearing agreed congestion existed online, nine speakers did not have an opinion, and two stakeholders did not feel congestion was actually an issue for ISPs.

To illustrate some of the responses of the stakeholders, primary examples will be drawn upon from the hearing; Rogers is an example of an ISP who believed congestion existed online. Rogers' brought up the issue of congestion in their presentation, and used an example to explain what was happening to their networks. Rogers stated that:

"The use of our network for constant 24/7 machine-to-machine traffic puts a strain on our network that, as a consumer grade Internet service, it is not intended to support. Think of our network as a highway with many lanes shared by many more cars. If one car ties up a whole lane 24 hours a day, it creates a problem for the other cars. That is exactly what peer-to-peer filesharing applications do and that is why we must manage this traffic. All other traffic on the network can use the entire upstream pipe" (CRTC, "Volume 5", 2009: 4917).

This example helps demonstrate the high volume of congestion that Rogers believes is occurring on their networks. Other ISPs, and even smaller businesses and interest groups did not entirely reject the notion that congestion could exist online. Even the Open Internet Coalition did not entirely deny the ISPs suggestion that congestion exists online; however as noted two stakeholders did not agree that congestion online was an issue. For example, CAIP's presentation questioned if congestion actually existed online. CAIP presented that it, “...does not believe the network congestion considerations should drive policy determinations regarding ITMPs”, and that “...a common industry definition of 'network congestion' in IP networks needs to be developed" (CRTC, "Volume 4", 2009: 2985). Interestingly, the findings of this analysis highlight that the vast majority of stakeholders, did enter the hearing with some sort of assumption that congestion is an actual problem in which ISPs have to overcome (Figure 7). 
Figure 7

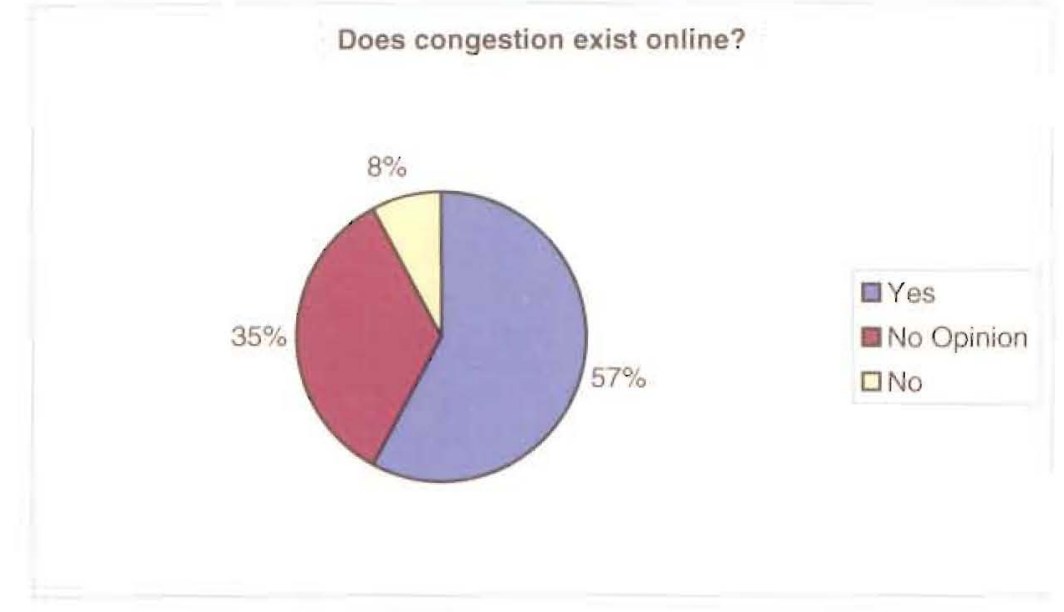

The second research question examined the issue of congestion in regard to the use of peer-to-peer file sharing online. It was clear from the beginning of the hearing that the CRTC panel already assumed that peer-to-peer file sharing was a key cause of online congestion. However, many stakeholders presented opposite opinions on this matter, despite ISPs continuing to suggest peer-to-peer file sharing was a key cause of high traffic volume online. Eleven of the stakeholders at the hearing felt that peer-to-peer file sharing was the main cause of online congestion, and nine speakers argued that it was not; six stakeholders did not take a stance on this issue at the hearing. Thus, the opinions on this issue were closely divided on whether it did or did not cause congestion (Figure 8).

Figure 8 


\section{Does Peer-to-Peer sharing cause network \\ congestion?}
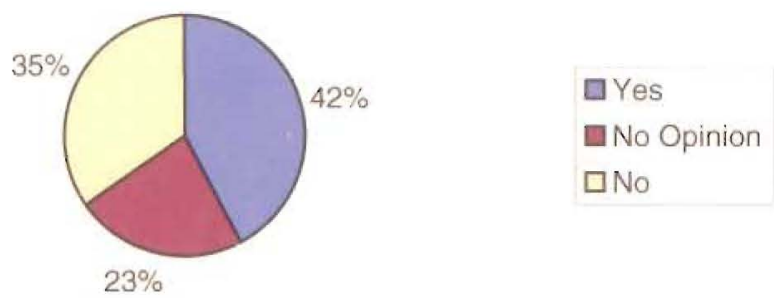

$\square$ No

Finally, the third content analysis counted the frequencies of three words throughout the hearing; the word congestion was utilized 526 times throughout the hearing, and the day it was used most frequently was on the first day of the seven-day hearing. However, after a close reading of the transcripts, it is evident that Bell received the most questions regarding this topic from the panel, and spent the most time addressing network congestion concerns than any other stakeholder at the hearing.

Surprisingly, the word discrimination, or discriminatory did not appear as frequently throughout the hearing as expected by the initial research presumptions. During the seven-day hearing, it was only used 156 times in the transcripts. Of the seven days, $25 \%$ of its usage came from the seventh day; like the word congestion, discrimination was used the most during Bell's presentation and question period of the hearing. The word competition, or competitive had a frequency of 184 uses throughout the hearing; on day four, it was spoken 61 times amongst the CRTC panel, and the four presenters. Again, this reveals that this term was not brought up as frequently as expected, but nonetheless, it is interesting to document what day each of the three words appeared the most frequently, and how often each word was utilized throughout the discussions. 


\section{Conclusions of Content Analysis 2 and 3}

These content analyses are relevant to consider in relation to the first content analysis explored in this essay; the first content analysis, which explored the various value perspectives amongst stakeholders, left some unanswered questions that needed to be explored in secondary content analyses. The themes of competition, congestion, and discrimination were touched upon in the first analysis in discussion and findings section of the report; also, the first analysis raised additional questions regarding whether the speakers at the hearing unanimously agreed congestion exists online, and if congestion is caused primarily by peer-to-peer traffic. Congestion and the targeting of specific applications online were concerns raised throughout the seven-day hearing, and stakeholders did not unanimously agree on either issue. However, as the findings of this content analysis conclude, the majority of stakeholders at the hearing did argue that congestion exists online, and peer-to-peer traffic was a source of congestion.

Thus the findings of the three content analyses provide documentation of each presenter's stance on a variety of values and issues that are relevant to consider in relation to the Internet neutrality debate; the analyses of the CRTC hearing demonstrates how each stakeholder had unique, but often similar stances on the use of Internet traffic management practices. Larger network players, like Shaw and Cogeco, tended to share similar value responses, whereas smaller businesses and representatives of consumer interest groups had a wider range of responses to the research questions used to analyze their positions at the hearing. 


\section{Introduction to Critical Discourse Analysis of CRTC Hearings}

Since the values of each stakeholder have already been analyzed, and additional research questions and issues have been assessed quantitatively, it is important to tie together the main themes of the CRTC hearing, in relation to the larger policy debate of Internet neutrality in Canada through a more qualitative approach as well. A critical discourse analysis is a flexible methodological approach to answering questions regarding a certain area of discourse. According to Norman Fairclough a, "Critical discourse analysis provides a way of moving between close analysis of texts and interactions, and social analyses of various types. Its objective is to show how language figures in social processes" (Fairclough, 1999). By definition, discourse is not a neutral device for communicating meanings, because people seek to accomplish things when they talk or write (i.e. there is usually an underlying reason or point for writing a text); a discourse analysis is concerned with the strategies they employ in trying to create different kinds of effect (Bryman and Teevan, 2005).

This critical discourse analysis is employed to search for a purpose regarding the way things were said or presented or presented at the CRTC hearing, and it also considers the influence of social factors outside of talk. Primarily, the theoretical framework that is grounding the exploration of the Internet neutrality discourse in Canada reflects a critical political economy approach. As outlined by Mosco (2009), a critical political economy background analyzes texts (blogs, journals, newspaper articles, etc.) in order to understand media processes, in this instance net neutrality, in its precedent context. Also its theoretical framework is correlated to wider concerns of social distribution of material resources. Thus, there is perhaps an underlying problem with the way in which the 
Internet, if one considers it to be a resource, is being distributed due to social context, which will be brought to surface through this investigation. With a critical political economist background, the ultimate aim of this segment of the research is to critically understand how power and ideology influence media communication, and specifically, what are the underlying reasons for arguing for or against Internet neutrality and to analyze how its language reflects a power struggle between consumers and providers of the Internet.

One key element to this discourse is connecting how the conversation at the CRTC hearing, and the ruling the CRTC made in response to the hearing, were impacted and influenced by the values of the top six Internet network providers (which will be revealed in this section). The Internet, as a resource, is highly controlled by these large ISPs, which makes Bell and Rogers examples of two important players in the discourse around Internet traffic management practices, which could impact Internet neutrality in Canada. Closely examining the underlying power structures that influence the way in which the Internet is being utilized and managed by underlying power structures through a critical discourse analysis is a unique approach to cohesively connect the discourse of the CRTC hearing on Internet traffic managements, to the larger context of Internet neutrality in Canada. The main strength in utilizing a discourse analysis is that it challenges researchers to question policy-making processes, and how power relations construct central discourses and marginalizes others. These areas of inquiry allow researchers to be reflective, and to question the research topic in an approach that may have not have otherwise been measured in other research methodologies. 


\section{Findings of the Discourse Analysis}

This discourse analysis reveals a number of interesting themes which arose throughout the transcripts of the CRTC hearing in relation to the Internet neutrality debate. Firstly, the issue of whether traffic management practices are the only ways ISPs are able to cope with traffic congestion was a reoccurring question throughout the sevenday hearing. As the content analysis portion of this research already noted, each stakeholder's response to the issue of whether congestion truly existed online, and what the cause of traffic congestion online was, varied from speaker to speaker. An overwhelming theme amongst ISPs was that peer-to-peer file sharing applications, such as BitTorrent, need to be regulated by traffic management practices. However, as it has also been previously illustrated with the content analysis portion of this research, a variety of independent content producers and distributors use peer-to-peer traffic sharing as a means to share their content online. Thus, targeting this application clearly puts smaller content producers and distributors at a disadvantage online if this content cannot be accessed as quickly as other applications. While Rogers and other Canadian ISPs do not want to create their own content in fear that it would be an anti-competitive move, there are obvious plans to expand their television programming to be accessible online, initiatives that were not included in the discussion at the hearing.

For example, Rogers has released their own web application named Rogers On Demand, which permits Roger's subscribers to stream programs on their computer that are normally accessible on television. A statement released by Rogers about their web program states this newer service means that, "Rogers Digital Cable customers can also join to watch many of the same subscription-based specialty channels online as they have 
through their television account"(Mudhar, 2009). Similarly, in 2008, Bell had released Bell Video Store before Rogers, which was a program that allowed Bell subscribers to download videos of DVD quality. However, this project was abandoned shortly after its release in July 2009 in order for Bell to focus its attention on Bell TV online. Bell TV, like Rogers on Demand, allows subscribers to: "access to things like the program guide, the ability to purchase pay-per-view content to later watch on the TV, and to view movie trailers" (Persaud, 2009). Thus, Rogers and Bell are two ISPs who also have shares in other forms of media; since television programs are increasingly becoming accessible online, Bell and Rogers surely will want to ensure that ITMP do not target the sites which host and stream their programs.

Also, peer-to-peer file sharing applications may be linked to the problem of downloading and uploading of illegal content online (i.e. movies, television shows, and other mediums with copyright restrictions on how and who has the right to distribute a title). An underlying assumption, likely made by ISPs who target peer-to-peer file sharing, is that applications such as BitTorrents allow Canadian Internet subscribers to access these copyrighted materials without paying a fee. But ISPs defended this argument at the hearing; for example Rogers suggested at the hearing that:

“...we do not care whether the applications are peer-to-peer file sharing or any other application, it is the $24 / 7$ maximum use of the network that creates problems. We would manage any other traffic with these characteristics the exact same way. We are not concerned with the nature of the content or whether it is legal or not. This protocol is designed to swamp the network and that is why it must be managed" (CRTC, "Volume 6", 2009:4981).

Despite Rogers' statement at the CRTC hearing, it still seems plausible that Bell and Rogers would be two ISPs who would be concerned about whether subscribers were using their services to download illegal content; since BitTorrents are often used to share 
illegal files, such as newly released movies, these files could potentially create a higher surge of traffic online. However, many Canadians simply do not know how to use peerto-peer file sharing applications such as BitTorrent, so the number of subscribers who use these programs is actually quite small.

Also, some speakers at the hearing presented opposite evidence in response to peer-to-peer file sharing 'swamping' networks. In illustration of this point, Jean FrancoisMezei's presentation claimed that users are limited by speeds, i.e. $5 \mathrm{Mbps}$, and it is not possible to download eleven times more than other users. Also he argued that networks have no business suggesting that peer-to-peer file sharing unfairly takes up bandwidth and uses the example of how now out of business Bell store once allowed for full 5MB per second downloading without throttling when it used as much bandwidth as a P2P download. Also, he examined the use of the popular video streaming site, YouTube, as a source for high traffic congestion online. Mezei stated that, "YouTube is an interesting phenomena because it's now the biggest user of bandwidth on the Internet and they're getting into HD movies"(CRTC, "Volume 2", 2009: 1714). Due to the fact that YouTube videos use one link, this is less efficient than using peer-to-peer applications, because it shares the bandwidth with several users. Thus, ISPs are not looking at how much bandwidth is actually being used, and are really concerned with the files the application shares, despite the statements released at the hearing in response to peer-to-peer file sharing. As Mezei puts forth, ISPs could not get away with throttling YouTube because too many subscribers would be infuriated with their service; whereas peer-to-peer file sharing gets targeted because it is still on the brink of its peak in popularity online. 
Perhaps another underlying reason why ISPs throttle is because YouTube's content is regulated by its moderators, meaning that illegal content usually quickly gets removed from its site, whereas peer-to-peer file sharing applications are not regulated by copyright restrictions. The value from the previous content analysis, authority, becomes a relevant motivation to consider in regard to throttling peer-to-peer applications because ISPs do not have the authority to manage what kinds of content subscribers view online, but their ability to slow down a user's ability to use peer-to-peer file sharing applications signifies that ISPs would like some sort of control over how people access content online. From a political economy perspective, ISPs are able to justify targeting these applications with traffic management practices because of congestion issues it could potentially create, if more people in their network utilized these sorts of applications. However, the reality is that Bell and Rogers likely do not only target peer-to-peer file sharing applications not only for its potential congestion issues it could cause on its networks, but peer-to-peer file sharing applications are also targeted by traffic management practices because often BitTorrent files are copyrighted materials. Logically, Bell and Rogers would target the application, which could potentially compete with their own online services for video distribution.

In relation to the value wealth, which was discussed in the content analysis section of this research, large network providers, and media conglomerates like Bell and Rogers are highly motivated and concerned with how profitable they can make their online services. Bell and Rogers are major stakeholders in more then one medium, but the Internet has the most potential to still grow and profit overtime as its usage continues to increase slowly across Canada. The area for film or television content distribution to 
grow is online, and Bell and Rogers are very aware of how many Canadians are turning to the Internet to access their favourite programs. Thus, wealth is an important value to consider in explaining and exploring why peer-to-peer file sharing applications are being targeting by traffic management practices; if more Canadians were to download illegal files, there would be even fewer business opportunities for media conglomerates like Bell and Rogers to profit from their online video services.

Another interesting area and theme of discourse that arose from the transcripts of the CRTC hearing is the assertion that congestion exists online. At the hearing, the transcripts reveal the various traffic management practices of each ISP; for example Cogeco admitted to throttling traffic all day, Bell throttles for large periods of the day, Shaw throttles only during busy or peak times, and Telus and Videotron did not admit to using any traffic management practices, such as bandwidth throttling. Many of the ISPs who admitted to using traffic management practices, made statements which would suggest that values such as freedom, and equality were important consumer rights. However, ISPs often evoked the values freedom and equality to justify why congestion needs to be combated by traffic shaping practices. For example, Shaw stated on the sixth day of the hearing that:

"We agree with the Commission's stated objective, to protect the interests of consumers and respect the ability of ISPs to effectively and efficiently manage our networks. These are not competing objectives. Our customers have always been our number one priority. This relentless focus on serving the needs of our customers drives us to constantly invest, innovate, launch new lines of business, and deliver exceptional customer service" (CRTC, "Volume 6", 2009: 5605).

The statement above is a clear indication that ISPs, and smaller businesses and consumer groups have different notions of what freedoms and rights Canadian Internet consumers should have online. The stakeholders, and advocates for Internet neutrality view targeting 
specific traffic online as a violation of online consumer rights and freedoms. The Open Internet Coalition argued that:

“...practices that undermine the Internet's openness are bad for innovation; in this case, application-specific traffic management practices. ITMPs that discriminate between applications distort market forces and harm user choice. Very simply, when one particular application is slower than others it is less attractive to users. Giving carriers the power to slow down applications at their own discretion will change user behaviours, distort innovation and undermine the competitive market in applications (CRTC, "Volume 2", 2009: 1016).

Thus by targeting specific applications, such as BitTorrent, ISPs truly do not consider rights and freedoms to be a primary concern if it impacts the efficiency of their networks. As the CRTC ruling suggests, traffic management practices, such as bandwidth throttling, should always be used as a last resort; also, if congestion truly exists online, targeting competing applications and services online cannot and should not be the primary solution in alleviating the traffic.

As a final point, the last area of discourse that will be examined is the issue of competition; this issue has already been previously touched upon in relation to accessing diverse content online, differentiating wholesale services from larger network players, and concentration of media ownership. Competition was an important theme of the discourse surrounding the traffic management practices hearing, and was touched upon in numerous presentations by the stakeholders in a variety of arguments. Notably, there was quite a difference in opinion regarding whether competition in the marketplace, in relation to online content, and ISP consumer choice, was thriving in Canada. Large ISPs felt that the marketplace was highly competitive, and thriving in relation to consumer choice; however, Jason Roks' presentation reminded the CRTC how Canadian consumers do not have much choice in which ISP they subscribe to for their services. He explains: 
"Unfortunately, we don't have a competitor. We do not have one-to-one competition in this country. You have competing technologies that are being called competitive. DSL and cable don't compete. They both do broadband, but they are different technologies. For me to switch from one to the other, I have to replace my modem, I have to deal with different issues. The same with switching from, say, Bell's phone to Rogers' phone. One is using GSM and one is using another. That is not a valid competitive choice. I have to get a new phone. I am locked, based on the way competition is defined in this country" (CRTC, "Volume 2", 2009: 1878).

If ISPs cannot handle the amount of subscribers using their networks, Roks suggests that these ISPs should stop signing on new users, and refrain from advertising upload and download speeds that their networks can no longer achieve. Roks points out that ISPs are falsely advertising their services to Canadians, and those who are subscribing to these providers are not receiving the services they are paying for monthly. If ISPs are unwilling to allow smaller wholesale providers to differentiate their services, and if they continue to extend traffic shaping practices to their wholesale customers, this creates an anticompetitive marketplace. Consumers should have the right to choose from a variety of online services, but large network players such as Bell, already deem the ISP market share to be competitive enough.

six main ISPs in Canada, account for about three quarters of the Internet subscription market. As Figure A illustrates, there are only six main Internet service providers for Canadians to subscribe to across the nation; while this number initially may not sound like too much concentration of ownership, the reality is that only one or two of these ISPs will be available in a region, meaning that a Canadian consumer could choose a smaller wholesale provider as an ISP, but many Canadians are simply unaware of these alternatives or choose larger ISPs such as Bell or Rogers because they can offer bundled services, such as telephone connections, or access to cable/satellite television. 
Thus, this discourse analysis demonstrates that there were a variety of reoccurring themes throughout the hearing, which are relevant to consider in relation to some of the previous values assessed during the content analysis. The discourse surrounding Internet neutrality, and traffic management policy were studied primarily by examining the dialogues that took place during the seven-day hearing. The discourses around this area of telecommunications policy were influenced by external factors, which were qualitatively explored in this analysis. Policy discourses, like Internet neutrality, are constantly produced and reformed through social relations, and most importantly, communication regarding the topic is not restricted to the realm of policy makers (such as the CRTC, or ISPs themselves), but it also includes a variety of disciplines, and outlooks that also present dialogue which may influence the way in which policy is shaped.

The final CRTC ruling was not a complete loss for Internet neutrality advocates, and it was not a complete gain for ISPs (however, one would argue that the CRTC ruled more in favour of the demands of ISPs than the other stakeholders who spoke at the hearing). The CRTC established several key requirements for Canadian ISPs, which include transparency obligations that force ISPs to disclose their network management practices. ISPs must explain to the public why management practices are being used, which users will be impacted by ITMP, when ITMP will happen, and what are the effects of ITMP on the user's experience (including disclosing how connection speeds could be impacted) (Geist 2010). Thus some of the concerns of stakeholders who opposed ITMP were addressed, but Geist's article, written shortly after the CRTC issued ITMP rules, highlights how some of the ISPs have not entirely complied with the guidelines. For example, Geist notes that Telus and Videotron do not have explicit network management 
practice disclosures since neither of them currently uses throttling, or traffic shaping technologies that limit the speeds of some applications. Of the four remaining top six providers in Canada, “...none makes it easy to find the disclosures and at least two may not be compliant with the CRTC requirements" (Geist, 2010). Interestingly, Bell, who at the hearing definitely received the most scrutiny for using ITMP, has the most detailed disclosure, and has followed the guidelines presented by the CRTC in October 2009. However, Geist (2010) notes: "The Rogers policy is not quite as extensive, yet it also covers much of the same terrain, including a description of the policy, the frequency of traffic shaping and the resulting limitations in its service (including the specific impact on speed." Interestingly, the final two of the top six service providers, fall short in meeting the CRTC's guidelines regarding ITMP. Shaw and Cogeco are less transparent in their disclosure of how ITMP will impact their subscribers; for example, Shaw and Cogeco's policy does not disclose the actually speeds users encounter when it throttles peer-to-peer activity.

However, Geist (2010) reports that the way in which traffic is being managed has hardly changed since the presentations at the hearing; Telus and Videotron do not use throttling technologies, and only use economic measures (such as charging heavy downloaders with an additional fee) to manage traffic on their networks. Meanwhile, Rogers and Cogeco continue to throttle all upstream peer-to-peer traffic, and "Both providers admit that the limits on their service occur on a 24 hour, 7-day basis, regardless of whether the network is actually experiencing any congestion" (Geist, 2010). Thus while the CRTC's guidelines did have some success in ensuring there is more transparency for Canadian subscribers, ISPs are keeping a lot of information regarding 
how they use ITMP private. Throttling traffic all day still means that ISPs are not just using ITMP when there are peak times of congestion, or when these instances occur. Evidently, how ITMPs, such as throttling, and DPI are being used by ISPs, has not changed very much following the ruling from the CRTC hearing. ISPs have to be more transparent about the traffic management practices, which means consumer rights were a value that the CRTC considered to be important to consider. However, not much else changed as a result of the hearing; ISPs still can manage their networks as they deem necessary (with some limitations), and smaller content producers and distributors will continue to have their peer-to-peer files targeted by traffic shaping managements. Nonetheless, the discourse around the Internet neutrality debate, and traffic management practices will continue to be an interesting area of investigation that deserves more attention from Canadian telecommunication policy academics in the future. Since the CRTC has yet to issue an actual hearing just examining Internet neutrality in Canada, it seems likely that this is an area of policy debate that may receive its own hearing one day.

\section{Brief Update on the Internet Neutrality Debate in Canada since the Traffic}

\section{Management Practice Hearing Ruling in October 2009}

After the ruling on the Internet traffic management practices in October, 2009, some of the stakeholders who spoke at the hearing pursued more Internet neutrality protection for mobile Internet services. In June 2010 the Canadian Internet Policy and Public Interest Law Clinic (CIPPIC), acting with OpenMedia.ca, alongside several ISPs, the Canadian Wireless Teleconmmunications Association (CWTA) and the Public Interest 
Advocacy Centre, was triumphant in an appeal to the CRTC that the Internet traffic management policies on net neutrality be applied as well to the mobile Internet (CRTC, “Telecom Decision 2010-445", 2010). According to CIPPIC, these new rules stipulate that:

“...service providers will only be permitted to discriminate by throttling particular mobile data services where there is a problem that cannot be addressed by without throttling, and where the chosen method of throttling is narrowly tailored to the problem and minimally intrusive of user experiences" (CIPPIC, 2010).

Since smart-phones, such as Blackberries, and iPhones are increasingly being used by

Canadians as a means to access the Internet, it was an important gain for Internet neutrality advocates that there is no differential treatment of how the Internet is being accessed, whether it be by a phone or a computer. However, it is possible that ISPs and mobile phone service providers such as Telus, Bell and Rogers will eventually reevaluate what types of traffic management practices are appropriate for their mobile Internet users; one can speculate that the online content and applications that an individual uses on their phone slightly varies from the way in which users use their Internet from their computers, since some applications on smart-phones are restricted (for example, Flash videos cannot be viewed on the iPhone). Nonetheless, it is promising that the CRTC recognizes that smart-phones in Canada also heavily utilize the Internet, and that policy measures need to extend to the Internet's mobile users.

\section{Final Thoughts and Conclusions on Research Findings and Research Goals}

In summary, the research conducted throughout this essay has examined the issue of Internet neutrality using a variety of methodologies. The research focused on connecting the issue of Internet neutrality to the CRTC hearing, which examined ITMP. 
Traffic management practices utilized by ISPs, who own the broadband that millions of Canadians subscribe to, ultimately must be thought of as an Internet neutrality issue because they interfere with its open architecture. The Internet once was left largely unregulated and unmanaged by the CRTC and ISPs, but as congestion continues to increase due to more bandwidth being utilized by Internet users, keeping the Internet free from corporate or government constraints is increasingly no longer the case in Canada. While Internet neutrality is a multi-faceted debate, traffic-shaping practices are ultimately a concern for those who are advocates of network neutrality. Whether ITMP harm innovation, competition, accessibility, and a user's experience online are all themes that are relevant to the Internet neutrality discourse. As the literature review proponent of this research illustrated, Internet neutrality is a heavily contested issue amongst the scholars and activists who have written on the subject.

Also, the review of the literature written on the subject explored some of the key arguments for and against Internet neutrality. However, many of the key arguments made for keeping the Internet neutral are also used in opposition of Internet neutrality. For example, advocates for network neutrality often suggest that innovation will be hindered online if ISPs manage their networks in a manner that may give preferential treatment to some applications and sites over others. Notably, innovation has always been a key element of the development of the Internet; however whether innovation will be jeopardized by more ISP intervention is still a questionable area of discussion. Those who are against Internet neutrality often argue otherwise; opponents of network neutrality suggest that innovation will suffer if ISPs do not manage online traffic congestion. If there is too much congestion online, users will increasingly become frustrated with their 
subscriptions, and the quality of their experience online will deteriorate. Also, scholars such as Anderson, who also spoke at the CRTC hearing on traffic management practices, examined the historical roots of the guiding principles behind the term network neutrality; its framework can be traced to the policy of 'common-carriage', meaning that no service should receive preferential treatment over others. However, some scholars who have examined the debate have proposed that the current state of the Internet is not currently neutral. For example, if one were to type a phrase into Google's search-bar, the Wikipedia write-up is always one of the first sites to appear as a link; thus certain websites are already given preferential treatment online, without regulation. Thus, there are conflicting arguments and dialogue amongst scholars who have examined the Internet neutrality debate. However, as mentioned throughout the essay, Canadian scholars have not paid as much attention to this topic as American academics, so much of the literature examined in this section reflects an American perspective of the debate. The dilemmas of the Internet are an ongoing development, as the medium continues to grow in subscribers. Importantly, the literature that does pertain to the Internet neutrality dispute highlights the key arguments for those in favour and against online regulation. However, in the last two years, more literature is starting to emerge on the subject; this is an important step towards encouraging more Canadians, not just scholars, to familiarize themselves with the issue.

Undeniably, despite the fact that the 'Communications Monitoring Report' from July 2010 revealed that $95 \%$ of Canadians have access to broadband networks, the reality is that most Canadian Internet users do not know what the term Internet neutrality means. For example, when the Public Interest Advocacy Centre (PIAC), who also spoke on the 
second day of the CRTC hearings on traffic management practices, conducted focus groups in Canada in order to investigate the Canadian public response to the Internet neutrality debate, it was noted that most Canadians are unaware of how the government is intervening in the whole policy debate. The report indicates that many Canadians are not cognizant of the current debates over net neutrality, but "...consumers are aware and concerned about a number of issues that touch on the concept of net neutrality - for example, universal access, privacy issues, censorship on the Internet and commercialization of the Internet" (Public Interest Advocacy Centre 2009). Thus, while many Canadians are uncertain what the term "Internet neutrality" means, Internet users in Canada are progressively becoming more concerned about the Internet being regulated by both the CRTC and ISPs. As it has been suggested, many Canadians are simply unaware that ISPs are utilizing such methods when they are using their Internet services. This is problematic as well because Canadians cannot complain to large ISPs if they are unaware of Internet neutrality issues.

While one can hope that the CRTC's ruling on traffic management practices can help regulate how often ISPs use traffic management practices that target specific applications, the ruling did not entirely stop ISPs from targeting peer-to-peer traffic online. This means that smaller content producers and distributors online could still have their content targeted by traffic shaping practices. Also, ISPs who do have stakes in other mediums will always have an upper hand over independent content online, because ISPs will never use traffic shaping methods that would target their own affiliated sites and businesses on the Internet. Furthermore, since the hearing on traffic management practices, the CRTC has scheduled another hearing, which will examine the effects of 
vertical integration in June 2011; the various presentations from stakeholders will likely follow-up on numerous questions that were left unanswered at the CRTC hearing on traffic management practices, such as the lack of competition amongst media conglomerates. Large network players, such as Bell and Rogers, will again have to appear in front of a CRTC panel and address concerns regarding diversity, and competition of ownership. Whether Internet neutrality issues will be at all connected to this hearing, and what sort of dialogue will occur amongst the presenters at the hearing, will be an area of research that will be interesting to watch unfold.

After exploring the literature, and examining some of the Internet neutrality issues that had been occurring in Canada prior to the traffic management practices hearing, two forms of primary research were employed to investigate the transcripts from the sevenday dialogue. The content analysis illustrates that it important to identify the values held by stakeholders at the hearing, and to understand the value differences among stakeholder groups. The six values selected from Schwartz' work provides an explanatory framework for understanding policy issues, and can be incorporated to predict and explain individual and societal choices related to ongoing policy debates. In the first content analysis, specific values were expressed in the form of different arguments; sometimes the same value was used to argue both side of the debate regarding traffic management practices. For example, freedom was a value that was argued to support regulation, and it was also used to argue against it; also some stakeholders argued that the influence of traffic management practices had a positive effect on Internet users, whereas other presenters suggested the complete opposite opinion on the matter. Thus, the six values that were examined throughout the first content analysis were all relevant to consider when 
examining the transcripts from the seven-day hearing. The data on the stakeholders illustrates that there were only a couple of dominant perspectives, expressed repeatedly by opposing groups, and some other ideas and groups had less entrenched views in response to the research questions selected in this methodology to analyze the transcripts. However, as the discourse analysis illustrated, certain values and themes in the dialogue at the hearing were expressed more frequently than others. The discourse analysis provides a qualitative approach in exploring and understanding the motivations that drive the arguments that stakeholders are making for or against traffic management practices; those who argue against traffic management practices usually were stakeholders who advocated for network neutrality principles. Whereas those who argued for traffic shaping of networks, presented arguments at the hearing that reflected an antinetwork neutrality stance. Undeniably, the hearing on traffic management practices can be closely linked to the overall Internet neutrality debate in Canada, since a major concern of network neutrality advocates is equal and fair access to diverse content online. This discourse analysis provides future guidelines that could help policy analysts and policy makers monitor value conflicts as this debate continues to evolve. While values do not necessarily determine how polices are enacted, values are arguably one of the key factors that inform agenda setting and decision-making.

To conclude, the Internet neutrality debate has not yet been resolved in Canada, and will continue to develop. One would hope that the CRTC one day convenes a hearing that solely discusses Internet neutrality in Canada; while Internet traffic management practices are relevant to the network neutrality debate, this hearing did not entirely address all the concerns, which surround the network neutrality debate. Therefore, greater 
attention to the topic may arise in the future. Also, the CRTC is likely to question Internet regulation and traffic management practices again in the future, but this projection is just speculation. Until the CRTC can ensure that ISPs are only using traffic management practices when necessary, Canadian users are vulnerable to the kinds of decisions ISPs are making on behalf of their subscribers. Thus after assessing the dialogue at the hearing, and reviewing the literature in the field, it becomes increasingly evident that network neutrality in Canada is wavering; as the Internet continues to become more commonly used to access information, and content, it becomes increasingly important that the CRTC ensures consumer rights and freedoms are not being hindered as a result of the great deal of control media conglomerates, such as Bell and Rogers, are exerting on their broadband networks. Traffic shaping practices can, and continue to threaten the open architecture that the Internet was founded upon; thus future policy measures could increase the amount of regulation on the Internet, which could either result in the CRTC exerting more control over how ISPs are managing their networks, or it could grant more power in the hands of a few dominant ISP market players. 


\section{APPENDIX A}

Speakers at CRTC hearing

\begin{tabular}{|l|l|}
\hline Day & Speakers in order of appearance \\
\hline 1 & Sandvine, Juniper, National Union, Public Interest Advocacy Centre \\
\hline 2 & Open Internet Coalition, Zip.ca, CISP, Jean Francois-Mezei, Jason Roks \\
\hline 3 & IFTA, CFTPA, CCD/ARCH, ACTRA, MTS Allstream \\
\hline 4 & $\begin{array}{l}\text { CAIP, CIPPIC, Execulink Telecom, Primus Telecommunications Canada, } \\
\text { Inc. }\end{array}$ \\
\hline 5 & Telus, Cogeco, Barratt Xplore \\
\hline 6 & Union des Consommateurs, Rogers, Videotron, Shaw \\
\hline 7 & Bell \\
\hline
\end{tabular}

The following six values have been assigned and defined to compare and assess the speaker's perspectives at the CRTC hearing in July 2009 regarding Internet traffic management practices. The definition of the term 'value' has already been provided in the essay.

Each variable will be given a definition and guidelines to illustrate how the research has been categorized for this content analysis. Only the researcher's definition of each category, and key terms can be used in this code application.

The six key values that were assessed are the following variables:

\section{Wealth}

2. Freedom

\section{Capable}

4. Influential

5. Equality

6. Authority

Each speaker will be coded as:

Positive $=1$ Neutral $=2$ Negative $=3$

Positive - Definition:

A positive rating will be given to the actor if it is perceived by the researcher that their presentation during the hearing reflects that it is for the value in question. Therefore the generals reflect the value in question in as positive, or the value is reflective of their own beliefs/concerns with the Internet management practices in question at the hearing.

Neutral - Definition:

A neutral rating will be given to the actor's position if there is no mentioning of encouraging or discouraging the value in question. Therefore a neutral rating suggests 
that the presentation did not present enough information on the value to be coded as negative or positive, or their position is somewhat in the middle of against or for the value being analyzed.

Negative - Definition:

A negative rating will be given to the actor's position reflects a negative position on the value in question. If an actor's presentation has been coded negative, it signifies that their position is against the value being assessed, and the actor does not favour the value in question in high regard.

\section{Variable 1: Wealth}

Wealth can be defined as the value related to money, material possessions, and valuable resources. I.e. is profitability a concern of the speaker? Are current Internet traffic management practices a concern to the speaker's future profitability?

Figure A

Day 1

\begin{tabular}{|l|l|l|l|}
\hline & Positive & Neutral & Negative \\
\hline Sandvine & 1 & & \\
\hline Juniper Networks & 1 & & \\
\hline National Union & & 2 & \\
\hline $\begin{array}{l}\text { Public Interest } \\
\text { Advocacy Centre }\end{array}$ & & 2 & \\
\hline
\end{tabular}

Day 2

\begin{tabular}{|l|l|l|l|}
\hline & Positive & Neutral & Negative \\
\hline $\begin{array}{l}\text { Open Internet } \\
\text { Coalition }\end{array}$ & & 2 & \\
\hline Zip.ca & 1 & & \\
\hline CISP & 1 & & \\
\hline $\begin{array}{l}\text { Jean Francois- } \\
\text { Mezei }\end{array}$ & 1 & & \\
\hline Jason Roks & & 2 & \\
\hline
\end{tabular}


Day 3

\begin{tabular}{|l|l|l|l|}
\hline & Positive & Neutral & Negative \\
\hline IFTA & 1 & & \\
\hline CFTPA & 1 & & \\
\hline CCD/ ARCH & & 2 & \\
\hline ACTRA & & 2 & \\
\hline MTS Allstream & 1 & & \\
\hline
\end{tabular}

Day 4

\begin{tabular}{|l|l|l|l|}
\hline & Positive & Neutral & Negative \\
\hline CAIP & 1 & & \\
\hline CIPPIC & & 2 & \\
\hline Execulink Telecom & 1 & & \\
\hline $\begin{array}{l}\text { Primus } \\
\text { Telecommunications } \\
\text { Canada Inc. }\end{array}$ & 1 & & \\
\hline
\end{tabular}

Day 5

\begin{tabular}{|l|l|l|l|}
\hline & Positive & Neutral & Negative \\
\hline Telus & 1 & & \\
\hline Cogeco & 1 & & \\
\hline Barratt Xplore & 1 & & \\
\hline
\end{tabular}

Day 6

\begin{tabular}{|l|l|l|l|}
\hline & Positive & Neutral & Negative \\
\hline $\begin{array}{l}\text { Union des } \\
\text { Consommateurs }\end{array}$ & & 2 & \\
\hline Rogers & 1 & & \\
\hline Videotron & 1 & & \\
\hline Shaw & 1 & & \\
\hline
\end{tabular}

Day 7

\begin{tabular}{|l|l|l|l|}
\hline & Positive & Neutral & Negative \\
\hline Bell & 1 & & \\
\hline
\end{tabular}


Figure B

\section{Total}

\begin{tabular}{|l|l|l|}
\hline Positive & Neutral & Negative \\
\hline 18 & 0 & 8 \\
\hline
\end{tabular}

The majority of representatives at the hearing valued wealth.

Figure C

\begin{tabular}{|l|l|l|l|}
\hline & Mean & Median & Mode \\
\hline Day 1 & 1.5 & 1.5 & 1.5 \\
\hline Day 2 & 1.4 & 1 & 1 \\
\hline Day 3 & 1.4 & 1 & 1 \\
\hline Day 4 & 1.25 & 1 & 1 \\
\hline Day 5 & 1 & 1 & 1 \\
\hline Day 6 & 1.25 & 1 & 1 \\
\hline Day 7 & 1 & 1 & 1 \\
\hline Daily Total Average & $1.3^{*}$ & 1 & 1 \\
\hline
\end{tabular}

* Rounded to the tenth decimal

\section{Variable 2: Freedom}

Freedom can be defined as the value that individuals can make their own choices, and express their own ideas and thoughts. I.e. is it important for Internet users to have individual freedoms online?

Figure D

Day 1

\begin{tabular}{|l|l|l|l|}
\hline & Positive & Neutral & Negative \\
\hline Sandvine & 1 & & \\
\hline Juniper Networks & 1 & & \\
\hline National Union & 1 & & \\
\hline $\begin{array}{l}\text { Public Interest } \\
\text { Advocacy Centre }\end{array}$ & 1 & & \\
\hline
\end{tabular}

Day 2

\begin{tabular}{|l|l|l|l|}
\hline & Positive & Neutral & Negative \\
\hline $\begin{array}{l}\text { Open Internet } \\
\text { Coalition }\end{array}$ & 1 & & \\
\hline Zip.ca & 1 & & \\
\hline
\end{tabular}




\begin{tabular}{|l|l|l|l|}
\hline CISP & & 2 & \\
\hline $\begin{array}{l}\text { Jean Francois- } \\
\text { Mezei }\end{array}$ & 1 & & \\
\hline Jason Roks & 1 & & \\
\hline
\end{tabular}

Day 3

\begin{tabular}{|l|l|l|l|}
\hline & Positive & Neutral & Negative \\
\hline IFTA & 1 & & \\
\hline CFTPA & 1 & & \\
\hline CCD/ARCH & 1 & & \\
\hline ACTRA & 1 & & \\
\hline MTS Allstream & 1 & & \\
\hline
\end{tabular}

Day 4

\begin{tabular}{|l|l|l|l|}
\hline & Positive & Neutral & Negative \\
\hline CAIP & & 2 & \\
\hline CIPPIC & 1 & & \\
\hline Execulink Telecom & & 2 & 3 \\
\hline $\begin{array}{l}\text { Primus } \\
\text { Telecommunications } \\
\text { Canada Inc. }\end{array}$ & & & \\
\hline
\end{tabular}

Day 5

\begin{tabular}{|l|l|l|l|}
\hline & Positive & Neutral & Negative \\
\hline Telus & & & 3 \\
\hline Cogeco & & & 3 \\
\hline Barratt Xplore & & & 3 \\
\hline
\end{tabular}

Day 6

\begin{tabular}{|l|l|l|l|}
\hline & Positive & Neutral & Negative \\
\hline $\begin{array}{l}\text { Union des } \\
\text { Consommateurs }\end{array}$ & & 2 & \\
\hline Rogers & & & 3 \\
\hline Videotron & & 2 & \\
\hline Shaw & & & 3 \\
\hline
\end{tabular}

Day 7

\begin{tabular}{|l|l|l|l|}
\hline & Positive & Neutral & Negative \\
\hline Bell - & & & 3 \\
\hline
\end{tabular}


Figure E

Total

\begin{tabular}{|l|l|l|}
\hline Positive & Neutral & Negative \\
\hline 14 & 5 & 7 \\
\hline
\end{tabular}

The majority of speakers viewed freedom as a positive value during the hearing.

Figure F

\begin{tabular}{|l|l|l|l|}
\hline & Mean & Median & Mode \\
\hline Day 1 & 1 & 1 & 1 \\
\hline Day 2 & 1 & 1 & 1 \\
\hline Day 3 & 1 & 1 & 1 \\
\hline Day 4 & 2 & 2 & 2 \\
\hline Day 5 & 3 & 3 & 3 \\
\hline Day 6 & 2.5 & 2.5 & 2.5 \\
\hline Day 7 & 3 & 3 & 3 \\
\hline Daily Total Average & 1.9 & 1 & 1 \\
\hline
\end{tabular}

\section{Variable 3: Capable}

Capable can be defined as the value or potential of doing something effectively or efficiently; also capable is relevant to competence. I.e. is policy capable of ensuring Internet traffic management practices are non-discriminatory or is policy necessary at all?

Figure G

Day 1

\begin{tabular}{|l|l|l|l|}
\hline & Positive & Neutral & Negative \\
\hline Sandvine & & & 3 \\
\hline Juniper Networks & & & 3 \\
\hline National Union & 1 & & \\
\hline $\begin{array}{l}\text { Public Interest } \\
\text { Advocacy Centre }\end{array}$ & 1 & & \\
\hline
\end{tabular}

Day 2

\begin{tabular}{|l|l|l|l|}
\hline & Positive & Neutral & Negative \\
\hline $\begin{array}{l}\text { Open Internet } \\
\text { Coalition }\end{array}$ & 1 & & \\
\hline Zip.ca & 1 & & \\
\hline CISP_ & & 2 & \\
\hline
\end{tabular}




\begin{tabular}{|l|l|l|l|}
\hline $\begin{array}{l}\text { Jean Francois- } \\
\text { Mezei }\end{array}$ & 1 & & \\
\hline Jason Roks & 1 & & \\
\hline
\end{tabular}

Day 3

\begin{tabular}{|l|l|l|l|}
\hline & Positive & Neutral & Negative \\
\hline IFTA & & 2 & \\
\hline CFTPA & 1 & & \\
\hline CCD/ARCH & 1 & & \\
\hline ACTRA & 1 & & \\
\hline MTS Allstream & 1 & & \\
\hline
\end{tabular}

Day 4

\begin{tabular}{|l|l|l|l|}
\hline & Positive & Neutral & Negative \\
\hline CAIP & & 2 & \\
\hline CIPFIC & 1 & & \\
\hline Execulink Telecom & 1 & & 3 \\
\hline $\begin{array}{l}\text { Primus } \\
\text { Telecommunications } \\
\text { Canada Inc. }\end{array}$ & & & \\
\hline
\end{tabular}

Day 5

\begin{tabular}{|l|l|l|l|}
\hline & Positive & Neutral & Negative \\
\hline Telus & & & 3 \\
\hline Cogeco & & & 3 \\
\hline Barratt Xplore & & & 3 \\
\hline
\end{tabular}

Day 6

\begin{tabular}{|l|l|l|l|}
\hline & Positive & Neutral & Negative \\
\hline $\begin{array}{l}\text { Union des } \\
\text { Consommateurs }\end{array}$ & 1 & & \\
\hline Rogers & & & 3 \\
\hline Videotron & & & 3 \\
\hline Shaw & & & 3 \\
\hline
\end{tabular}

Day 7

\begin{tabular}{|l|l|l|l|}
\hline & Positive & Neutral & Negative \\
\hline Bell & & & 3 \\
\hline
\end{tabular}

Figure $\mathrm{H}$ 


\section{Total}

\begin{tabular}{|l|l|l|}
\hline Positive & Neutral & Negative \\
\hline 13 & 3 & 10 \\
\hline
\end{tabular}

The majority of representatives positively valued whether the government was capable of using policy to regulate Internet traffic management practices.

Figure I

\begin{tabular}{|l|l|l|l|}
\hline & Mean & Median & Mode \\
\hline Day 1 & 2 & 2 & 2 \\
\hline Day 2 & 1.2 & 1 & 1 \\
\hline Day 3 & 1.2 & 1 & 1 \\
\hline Day 4 & 1.75 & 2 & 1 \\
\hline Day 5 & 3 & 3 & 3 \\
\hline Day 6 & 2.5 & 3 & 3 \\
\hline Day 7 & 3 & 3 & 3 \\
\hline Daily Total Average & 2.1 & 2 & 2 \\
\hline
\end{tabular}

\section{Variable 4: Influential}

Influential can be defined as the value that impacts individuals and actions; it is also a precondition for other actions and events. I.e. Are current Internet traffic management practices influencing people's Internet usage in a positive or negative way?

Figure J

Day 1

\begin{tabular}{|l|l|l|l|}
\hline & Positive & Neutral & Negative \\
\hline Sandvine & 1 & & \\
\hline Juniper Networks & 1 & & \\
\hline National Union & & & 3 \\
\hline $\begin{array}{l}\text { Public Interest } \\
\text { Advocacy Centre }\end{array}$ & & & 3 \\
\hline
\end{tabular}

Day 2

\begin{tabular}{|l|l|l|l|}
\hline & Positive & Neutral & Negative \\
\hline $\begin{array}{l}\text { Open Internet } \\
\text { Coalition }\end{array}$ & & & 3 \\
\hline Zip.ca & & & 3 \\
\hline CISP & & & 3 \\
\hline Jean Francois- & & & 3 \\
\hline
\end{tabular}




\begin{tabular}{|l|l|l|l|}
\hline Mezei & & & \\
\hline Jason Roks & & & 3 \\
\hline
\end{tabular}

Day 3

\begin{tabular}{|l|l|l|l|}
\hline & Positive & Neutral & Negative \\
\hline IFTA & & & 3 \\
\hline CFTPA & & & 3 \\
\hline CCD/ARCH & & & 3 \\
\hline ACTRA & & & 3 \\
\hline MTS Allstream & & & 3 \\
\hline
\end{tabular}

Day 4

\begin{tabular}{|l|l|l|l|}
\hline & Positive & Neutral & Negative \\
\hline CAIP & & & 3 \\
\hline CIPPIC & & & 3 \\
\hline Execulink Telecom & & & 3 \\
\hline $\begin{array}{l}\text { Primus } \\
\text { Telecommunications } \\
\text { Canada Inc. }\end{array}$ & 1 & & \\
\hline
\end{tabular}

Day 5

\begin{tabular}{|l|l|l|l|}
\hline & Positive & Neutral & Negative \\
\hline Telus & 1 & & \\
\hline Cogeco & 1 & & \\
\hline Barratt Xplore & 1 & & \\
\hline
\end{tabular}

Day 6

\begin{tabular}{|l|l|l|l|}
\hline & Positive & Neutral & Negative \\
\hline $\begin{array}{l}\text { Union des } \\
\text { Consommateurs }\end{array}$ & & & 3 \\
\hline Rogers & 1 & & \\
\hline Videotron & 1 & & \\
\hline Shaw & 1 & & \\
\hline
\end{tabular}


Day 7

\begin{tabular}{|l|l|l|l|}
\hline & Positive & Neutral & Negative \\
\hline Bell & 1 & & \\
\hline
\end{tabular}

Figure L

Total

\begin{tabular}{|l|l|l|}
\hline Positive & Neutral & Negative \\
\hline 10 & 0 & 16 \\
\hline
\end{tabular}

The majority of representatives negatively valued the influence of current Internet traffic management practices.

Figure M

\begin{tabular}{|l|l|l|l|}
\hline & Mean & Median & Mode \\
\hline Day 1 & 2 & 2 & 2 \\
\hline Day 2 & 3 & 3 & 3 \\
\hline Day 3 & 3 & 3 & 3 \\
\hline Day 4 & 2.5 & 3 & 3 \\
\hline Day 5 & 1 & 1 & 1 \\
\hline Day 6 & 1.5 & 1 & 1 \\
\hline Day 7 & 1 & 1 & 1 \\
\hline Daily Total Average & 2 & 2 & 2 \\
\hline
\end{tabular}

\section{Variable 5: Equality}

Equality can be defined as the value that represents the state of being equal, in regard to: rights, status, and opportunity. I.e. do network players and consumers have the same rights and opportunities?

Figure $\mathrm{N}$

Day 1

\begin{tabular}{|l|l|l|l|}
\hline & Positive & Neutral & Negative \\
\hline Sandvine & & 2 & \\
\hline Juniper Networks & & 2 & \\
\hline National Union & & & 3 \\
\hline $\begin{array}{l}\text { Public Interest } \\
\text { Advocacy Centre }\end{array}$ & & & 3 \\
\hline
\end{tabular}

Day 2

\begin{tabular}{|l|l|l|l|}
\hline- & Positive & Neutral & Negative \\
\hline
\end{tabular}




\begin{tabular}{|l|l|l|l|}
\hline $\begin{array}{l}\text { Open Internet } \\
\text { Coalition }\end{array}$ & & 3 \\
\hline Zip.ca & & & 3 \\
\hline CISP & & & 3 \\
\hline $\begin{array}{l}\text { Jean Francois- } \\
\text { Mezei }\end{array}$ & & 3 \\
\hline Jason Roks & & & 3 \\
\hline
\end{tabular}

Day 3

\begin{tabular}{|l|l|l|l|}
\hline & Positive & Neutral & Negative \\
\hline IFTA & & & 3 \\
\hline CFTPA & & & 3 \\
\hline CCD/ARCH & & & 3 \\
\hline ACTRA & & & 3 \\
\hline MTS Allstream & & & 3 \\
\hline
\end{tabular}

Day 4

\begin{tabular}{|l|l|l|l|}
\hline & Positive & Neutral & Negative \\
\hline CAIP & & & 3 \\
\hline CIPPIC & & & 3 \\
\hline Execulink Telecom & & 2 & \\
\hline $\begin{array}{l}\text { Primus } \\
\text { Telecommunications } \\
\text { Canada Inc. }\end{array}$ & 2 & \\
\hline
\end{tabular}

Day 5

\begin{tabular}{|l|l|l|l|}
\hline & Positive & Neutral & Negative \\
\hline Telus & & 2 & \\
\hline Cogeco & & 2 & \\
\hline Barratt Xplore & & 2 & \\
\hline
\end{tabular}

Day 6

\begin{tabular}{|l|l|l|l|}
\hline & Positive & Neutral & Negative \\
\hline $\begin{array}{l}\text { Union des } \\
\text { Consommateurs }\end{array}$ & & & 3 \\
\hline Rogers & 1 & & \\
\hline Videotron & & 2 & \\
\hline Shaw & 1 & & \\
\hline
\end{tabular}

Day 7 


\begin{tabular}{|l|l|l|l|}
\hline & Positive & Neutral & Negative \\
\hline Bell & 1 & & \\
\hline
\end{tabular}

Figure $\mathrm{O}$

Total

\begin{tabular}{|l|l|l|}
\hline Positive & Neutral & Negative \\
\hline 3 & 8 & 15 \\
\hline
\end{tabular}

The majority of the representatives did not believe that consumers and major network players had equal opportunities online due to Internet traffic management practices.

Figure $\mathrm{P}$

\begin{tabular}{|l|l|l|l|}
\hline & Mean & Median & Mode \\
\hline Day 1 & 2.5 & 2.5 & 2.5 \\
\hline Day 2 & 3 & 3 & 3 \\
\hline Day 3 & 3 & 3 & 3 \\
\hline Day 4 & 2.5 & 2.5 & 2.5 \\
\hline Day 5 & 2 & 2 & 2 \\
\hline Day 6 & 1.75 & 1.5 & 1 \\
\hline Day 7 & 1 & 1 & 1 \\
\hline Daily Total Average & 2.25 & 2.5 & 2.75 \\
\hline
\end{tabular}

\section{Value 6: Authority -}

Social power can be defined as the value of who controls or dominates citizens and resources. I.e. Does the CRTC have the authority to regulate the kinds of Internet traffic management practices that ISPs utilize on their broadband networks?

Figure Q

Day 1

\begin{tabular}{|l|l|l|l|}
\hline & Positive & Neutral & Negative \\
\hline Sandvine & & & 3 \\
\hline Juniper Networks & & & 3 \\
\hline National Union & 1 & & \\
\hline $\begin{array}{l}\text { Public Interest } \\
\text { Advocacy Centre }\end{array}$ & 1 & & \\
\hline
\end{tabular}

Day 2

\begin{tabular}{|l|l|l|l|}
\hline & Positive & Neutral & Negative \\
\hline
\end{tabular}




\begin{tabular}{|l|l|l|l|}
\hline $\begin{array}{l}\text { Open Internet } \\
\text { Coalition }\end{array}$ & 1 & & \\
\hline Zip.ca & & & 3 \\
\hline CISP & & 2 & \\
\hline $\begin{array}{l}\text { Jean Francois- } \\
\text { Mezei }\end{array}$ & 1 & & \\
\hline Jason Roks & 1 & & \\
\hline
\end{tabular}

Day 3

\begin{tabular}{|l|l|l|l|}
\hline & Positive & Neutral & Negative \\
\hline IFTA & 1 & & \\
\hline CFTPA & 1 & & \\
\hline CCD/ARCH & 1 & & \\
\hline ACTRA & 1 & & \\
\hline MTS Allstream & 1 & & \\
\hline
\end{tabular}

Day 4

\begin{tabular}{|l|l|l|l|}
\hline & Positive & Neutral & Negative \\
\hline CAIP & 1 & & \\
\hline CIPPIC & 1 & & \\
\hline Execulink Telecom & 1 & & \\
\hline $\begin{array}{l}\text { Primus } \\
\text { Telecommunications } \\
\text { Canada Inc. }\end{array}$ & & & 3 \\
\hline
\end{tabular}

Day 5

\begin{tabular}{|l|l|l|l|}
\hline & Positive & Neutral & Negative \\
\hline Telus & & & 3 \\
\hline Cogeco & & & 3 \\
\hline Barratt Xplore & & & 3 \\
\hline
\end{tabular}

Day 6

\begin{tabular}{|l|l|l|l|}
\hline & Positive & Neutral & Negative \\
\hline $\begin{array}{l}\text { Union des } \\
\text { Consommateurs }\end{array}$ & 1 & & \\
\hline Rogers & & & 3 \\
\hline Videotron & & & 3 \\
\hline Shaw & & & 3 \\
\hline
\end{tabular}

Day 7 


\begin{tabular}{|l|l|l|l|}
\hline & Positive & Neutral & Negative \\
\hline Bell & & & 3 \\
\hline
\end{tabular}

Figure R

Total

\begin{tabular}{|l|l|l|}
\hline Positive & Neutral & Negative \\
\hline 14 & 1 & 11 \\
\hline
\end{tabular}

The majority of representatives felt that the CRTC had the authority to regulate Internet traffic management practices that ISPs use on their networks.

Figure $S$

\begin{tabular}{|l|l|l|l|}
\hline & Mean & Median & Mode \\
\hline Day 1 & 2 & 2 & 2 \\
\hline Day 2 & 1.4 & 1 & 1 \\
\hline Day 3 & 1 & 1 & 1 \\
\hline Day 4 & 1.5 & 1 & 1 \\
\hline Day 5 & 3 & 3 & 3 \\
\hline Day 6 & 2.5 & 3 & 3 \\
\hline Day 7 & 3 & 3 & 3 \\
\hline Daily Total Average & 2.1 & 2 & 2 \\
\hline
\end{tabular}




\section{APPENDIX B}

The following content analysis assesses key questions that were addressed during the CRTC hearing on Internet traffic management practices. Each actor's response to the issue in question has been coded either: 1) Yes 2) No Opinion 3) No

The actor's response will be coded yes if the speaker responded positively towards the question, or presents an opinion that the researcher deems to be in agreement with the question posed.

The actor's response will be coded no opinion if the speaker did not respond either positively or negatively toward the issue in question during their presentation at the hearing. It also reflects that perhaps not enough information was provided during the presentation to answer the question with a yes or a no response.

The actor's response will be coded $\underline{\text { no }}$ if the speaker did not agree, or respond positively to the research question posed.

The following research questions were utilized in this content analysis:

Research question 1: Do ISPs need to use various Internet traffic management practices to combat congestion online?

Research question 2: Does Peer-2-Peer sharing a main source of congestion for ISPs?

Research question 1: Do ISPs need to use various Internet traffic management practices to combat congestion online?

Yes $=1$ No Opinion $=2$ No $=3$

Figure A

Day 1

\begin{tabular}{|l|l|l|l|}
\hline & Yes & No Opinion & No \\
\hline Sandvine & 1 & & \\
\hline Juniper Networks & 1 & & \\
\hline National Union & & 2 & \\
\hline $\begin{array}{l}\text { Public Interest } \\
\text { Advocacy Centre }\end{array}$ & & 2 & \\
\hline
\end{tabular}

Day 2

\begin{tabular}{|l|l|l|l|}
\hline & Yes & No Opinion & No \\
\hline
\end{tabular}




\begin{tabular}{|l|l|l|l|}
\hline $\begin{array}{l}\text { Open Internet } \\
\text { Coalition }\end{array}$ & 1 & & \\
\hline Zip.ca & & 2 & \\
\hline CISP & 1 & & \\
\hline $\begin{array}{l}\text { Jean Francois- } \\
\text { Mezei }\end{array}$ & & 2 & \\
\hline Jason Roks & 1 & & \\
\hline
\end{tabular}

Day 3

\begin{tabular}{|l|l|l|l|}
\hline & Yes & No Opinion & No \\
\hline IFTA & & 2 & \\
\hline CFTPA & & 2 & \\
\hline CCD/ARCH & & 2 & \\
\hline ACTRA & & 2 & \\
\hline MTS Allstream & 1 & & \\
\hline
\end{tabular}

Day 4

\begin{tabular}{|l|l|l|l|}
\hline & Yes & No Opinion & No \\
\hline CAIP & & & 3 \\
\hline CIPPIC & 1 & & \\
\hline Execulink Telecom & & & 3 \\
\hline $\begin{array}{l}\text { Primus } \\
\text { Telecommunications } \\
\text { Canada Inc. }\end{array}$ & 1 & & \\
\hline
\end{tabular}

Day 5

\begin{tabular}{|l|l|l|l|}
\hline & Yes & No Opinion & No \\
\hline Telus & 1 & & \\
\hline Cogeco & 1 & & \\
\cline { 2 - 4 } Barratt Xplore & 1 & & \\
\hline
\end{tabular}

Day 6

\begin{tabular}{|l|l|l|l|}
\hline & Yes & No Opinion & No \\
\hline $\begin{array}{l}\text { Union des } \\
\text { Consommateurs }\end{array}$ & & 2 & \\
\hline Rogers & 1 & & \\
\hline Videotron & 1 & & \\
\hline Shaw & 1 & & \\
\hline
\end{tabular}


Day 7

\begin{tabular}{|l|l|l|l|}
\hline & Yes & No Opinion & No \\
\hline Bell & 1 & & \\
\hline
\end{tabular}

Figure B

\section{Total}

\begin{tabular}{|l|l|l|}
\hline Yes & No Opinion & No \\
\hline 15 & 9 & 2 \\
\hline
\end{tabular}

Research question 2: Is peer-to-peer sharing a main source of congestion for ISPs?

Yes $=1$ No Opinion $=2$ No $=3$

Figure C

Day 1

\begin{tabular}{|l|l|l|l|}
\hline & Yes & No Opinion - & No \\
\hline Sandvine & 1 & & \\
\hline Juniper Networks & 1 & & \\
\hline National Union & & 2 & \\
\hline $\begin{array}{l}\text { Public Interest } \\
\text { Advocacy Centre }\end{array}$ & & 2 & \\
\hline
\end{tabular}

Day 2

\begin{tabular}{|l|l|l|l|}
\hline & Yes & No Opinion & No \\
\hline $\begin{array}{l}\text { Open Internet } \\
\text { Coalition }\end{array}$ & & 2 & \\
\hline Zip.ca & & & 3 \\
\hline CISP & & & 3 \\
\hline $\begin{array}{l}\text { Jean Francois- } \\
\text { Mezei }\end{array}$ & & & 3 \\
\hline Jason Roks & & & 3 \\
\hline
\end{tabular}

Day 3

\begin{tabular}{|l|l|l|l|}
\hline & Yes & No Opinion & No \\
\hline IFTA & & & 3 \\
\hline
\end{tabular}




\begin{tabular}{|l|l|l|l|}
\hline CFTPA & 2 & \\
\hline CCD/ARCH & & 2 & \\
\hline ACTRA & & & 3 \\
\hline MTS Allstream & & 2 & \\
\hline
\end{tabular}

Day 4

\begin{tabular}{|l|l|l|l|}
\hline & Yes & No Opinion & No \\
\hline CAIP & & & 3 \\
\hline CIPPIC & & & 3 \\
\hline Execulink Telecom & 1 & & \\
\hline $\begin{array}{l}\text { Primus } \\
\text { Telecommunications } \\
\text { Canada Inc. }\end{array}$ & 1 & & \\
\hline
\end{tabular}

Day 5

\begin{tabular}{|l|l|l|l|}
\hline & Yes & No Opinion & No \\
\hline Telus & 1 & & \\
\hline Cogeco & 1 & & \\
\hline Barratt Xplore & 1 & - \\
\hline
\end{tabular}

Day 6

\begin{tabular}{|l|l|l|l|}
\hline & Yes & No Opinion & No \\
\hline $\begin{array}{l}\text { Union des } \\
\text { Consommateurs }\end{array}$ & & & 3 \\
\hline Rogers & 1 & & \\
\hline Videotron & 1 & & \\
\hline Shaw & 1 & & \\
\hline
\end{tabular}

Day 7

\begin{tabular}{|l|l|l|l|}
\hline & Yes & No Opinion & No \\
\hline Bell & 1 & & \\
\hline
\end{tabular}

Figure D

\section{Total}

\begin{tabular}{|l|l|l|}
\hline Yes & No Opinion & No \\
\hline 11 & 6 & 9 \\
\hline
\end{tabular}




\section{APPENDIX C}

The following content analysis assesses how frequent certain words, as selected by the researcher, were utilized throughout the seven-day CRTC hearing on Internet traffic management practices.

The following words will be counted for how frequent it was utilized throughout the seven-day hearing:

1. Congestion

2. Discrimination/discriminatory

3. Competition/ competitive

Figure A

\begin{tabular}{|c|c|}
\hline Day & $\begin{array}{c}\text { Frequency of the word } \\
\text { 'congestion' during the } \\
\text { hearing }\end{array}$ \\
\hline Day 1 & 112 \\
\hline Day 2 & 101 \\
\hline Day 3 & 35 \\
\hline Day 4 & 100 \\
\hline Day 5 & 25 \\
\hline Day 6 & 90 \\
\hline Day 7 & 63 \\
\hline Total & 526 \\
\hline
\end{tabular}

Figure B

\section{Frequency of the use of the word 'congestion' daily during the CRTC hearing}
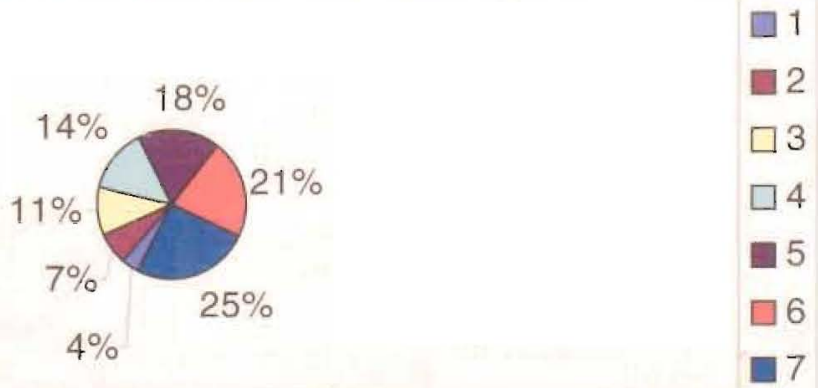

Day 7 only had one presenter (Bell), but the word congestion was utilized the most frequently on this day of the hearing. This analysis suggests that congestion was a heavily discussed issue during Bell's presentation. 
Figure C

\begin{tabular}{|l|l|}
\hline Day & $\begin{array}{l}\text { Frequency of the word } \\
\text { 'discrimination' or } \\
\text { 'discriminatory' during the } \\
\text { hearing }\end{array}$ \\
\hline Day 1 & 28 \\
\hline Day 2 & 19 \\
\hline Day 3 & 49 \\
\hline Day 4 & 14 \\
\hline Day 5 & 32 \\
\hline Day 6 & 11 \\
\hline Day 7 & 3 \\
\hline Total & $\mathbf{1 5 6}$ \\
\hline
\end{tabular}

Figure D

Frequency of the word(s) 'discrimination' or 'discriminatory' during the CRTC hearing

\begin{tabular}{ll}
$4 \%$ & $\square 1$ \\
$25 \%$ & $\square 2$ \\
\hline $18 \%$ & $\square 3$ \\
$11 \%$ & $\square 4$ \\
\hline & $\square 5$ \\
\hline & $\square 6$ \\
\hline & $\square 7$
\end{tabular}


Figure E

\begin{tabular}{|l|l|}
\hline Day & $\begin{array}{l}\text { Frequency of the word } \\
\text { 'competition' or 'competitive } \\
\text { during the hearing }\end{array}$ \\
\hline Day 1 & 3 \\
\hline Day 2 & 29 \\
\hline Day 3 & 26 \\
\hline Day 4 & 61 \\
\hline Day 5 & 29 \\
\hline Day 6 & 24 \\
\hline Day 7 & 12 \\
\hline Total & $\mathbf{1 8 4}$ \\
\hline
\end{tabular}

Figure F

Frequency of the word(s) 'competition' or 'competitive' during the CRTC hearing

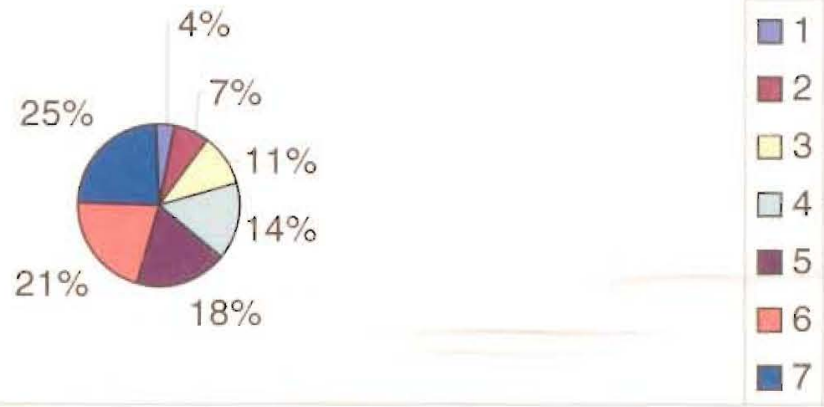


Anderson, N. (2009). How Canadian ISPs throttle the internet. Ars Technica website. Retrieved from:

$<$ http://arstechnica.com/business/news/2009/01/how-canadian-isps-throttle-theinternet.ars>

Anderson, S. (2009). Net neutrality: the view from Canada. Media Development, 8-11.

Barratt, N, \& Shade, L. (2007). Commentary net neutrality: telecom policy and the public interest. Canadian Journal of Communication, 32, 295305 .

Bryman, Alan and James J. Teevan. (2005). Social Research Methods - Canadian Edition. Toronto, CA: Oxford University Press.

Canada. (1993). "Telecommunications Act." Retrieved from: <http://lawslois.justice.gc.ca/eng/acts/T-3.4/>

"Canada's largest internet service providers." Digital Home. Retrieved from: $<$ http://www.digitalhome.ca/2009/11/canadas-largest-digital-serviceproviders/>

CBC News. (2008, September). Bell moves to disconnect small ISP for nonpayment. September 2 2008. Retrieved from:

< http://www.cbc.ca/money/story/2008/08/27/tech-

cybersurf.html?ref=rss $>$

CBC News. (2006 November). Battle over net-neutrality arrives in Canada. November 2, 2006. Retrieved from:

<http://www.cbc.ca/technology/story/2006/11/02/tech-neutrality.html>

CBC News. (2009, October). CRTC issues net neutrality rules. October 21, 2009. Retrieved from:

$<$ http://www.cbc.ca/technology/story/2009/10/20/crtc-net-neutralityruling.html>

Cheng, An-Shou, Kenneth R. Fleischemann, Ping Wang, Emi Ishita, and Douglas W. Oard. (2010) "Values of Stakeholders in the Net Neutrality Debate: Applying Content Analysis to Telecommunications Policy." Proceedings of the $43^{\text {rd }}$ Hawaii International Conference on System Sciences.

Chung, Emily. (2008). "Small ISPs fight ruling that let Bell throttle internet speeds." CBC News. Retrieved from: 
<http://www.cbc.ca/technology/story/2009/05/21/tech-bell-ispsinternet-throttling.html>

CIPPIC (Canadian Interest Policy and Public Law Clinic). (2010, June 30). "CRTC applies net neutrality rules to wireless providers." [Press release]. Retrieved from:

$<$ http://www.cippic.ca/index.php?mact=News,cntnt01,detail,0\&cntnt01 articleid= $462 \&$ cntnt 01 origid $=216 \&$ cntnt 01 dateformat $=\% 25 \mathrm{~B} \% 20 \% 25 \mathrm{e} \% 2 \mathrm{C} \% 20 \% 25 \mathrm{Y} \& \mathrm{c}$ ntnt01 returnid $=54$.

Cooper, M. (2006). "The importance of open networks in sustaining the digital revolution." In T. Lenard, \& R. May (Eds.), Net neutrality or net neutering - should broadband services be regulated? (pp. 109-161). Springer US.

CRTC. (2010, July). Communications Monitoring Report. Retrieved from: $<$ http://www.crtc.gc.ca/eng/publications/reports/policymonitoring/2010 /cmr2010.pdf $>$

CRTC. (2010, June). Telecom Decision - 2010-445: Modifications to forbearance framework for mobile wireless data services. Retrieved from: < http://www.crtc.gc.ca/eng/archive/2010/2010-445.htm.>

CRTC. (2008, December). Telecom Decision - 2008 - 117: Cybersurf Corp.'s application related to matching service speed requirements for wholesale Internet services. Retrieved from: <http://www.crtc.gc.ca/eng/archive/2008/dt2008117.htm>

CRTC. (2009, October). Telecom Regulatory Policy CRTC 2009-657. Retrieved from: <http://www.crtc.gc.ca/eng/archive/2009/2009-657.htm >

CRTC. (2009, July 6). "Volume 1." Transcript of Proceeding: Review of the Internet Traffic Management Practices of Internet Service Providers. Retrieved from: <http://www.crtc.gc.ca/eng/transcripts/2009/tt0706.htm>

CRTC. (2009, July 7). "Volume 2." Transcript of Proceeding: Review of the Internet Traffic Management Practices of Internet Service Providers. Retrieved from: <http://www.crtc.gc.ca/eng/transcripts/2009/tt0707.htm>

CRTC. (2009, July, 8). "Volume 3." Transcript of Proceeding: Review of the Internet Traffic Management Practices of Internet Service Providers. Retrieved from: <http://www.crtc.gc.ca/eng/transcripts/2009/tt0708.htm>

CRTC. (2009, July, 9) "Volume 4." Transcript of Proceeding: Review of the 
Internet Traffic Management Practices of Internet Service Providers. Retrieved from:

<http://www.crtc.gc.ca/eng/transcripts/2009/tt0709.htm>

CRTC. (2009, July 10). "Volume 5." Transcript of Proceeding: Review of the Internet Traffic Management Practices of Internet Service Providers. Retrieved from: <http://www.crtc.gc.ca/eng/transcripts/2009/tt0710.htm>

CRTC. (2009, July 11). "Volume 6." Transcript of Proceeding: Review of the Internet Traffic Management Practices of Internet Service Providers. Retrieved from: <http://www.crtc.gc.ca/eng/transcripts/2009/tt0711.htm>

CRTC. (2009, July 12). "Volume 7." Transcript of Proceeding: Review of the Internet Traffic Management Practices of Internet Service Providers. Retrieved from: <http://www.crtc.gc.ca/eng/transcripts/2009/tt0712.htm>

CRTC Public Notice. (1999). Call for comments on a proposed exemption order for new media broadcasting undertakings. 118. Retrieved from <http://www.crtc.gc.ca/eng/archive/1999/PB99-118.HTM>

CTV.ca. "Bell Canada parent BCE buys CTV. Inc for $\$ 1.3 B$." Retrieved from CTV.ca website. < http://www.ctv.ca/CTVNews/TopStories/20100910/ctv-bce-100910/>

Fairclough, Norman. (1999). "Linguistic and Intertextual Analysis within Discourse Analysis." The Discourse Reader. New York, NY: Routledge.

Geist, M. (2010, February). "ISPs fall short on Net Neutrality Rules." The Toronto Star. Retrieved from: $<$ http://www.thestar.com/news/sciencetech/technology/lawbytes/article/765521-geist-isps-fall-short-on-net-neutrality-rules>

Geist, M. (2008, March 26). "The Bell wakeup call." Retrieved from: < http://www.michaelgeist.ca/content/view/2787/125/>

Gilroy, Angele E. (2008). "Net neutrality: Background and issues." Congressional Research Service, Library of Congress, CRS Report for Congress, RS22444.

Globerman, Steven. (2008). “A Policy Analysis of Net Neutrality." Fraser Institute: Digital Publication. Retrieved from: <http://fraserinstitute.org/researchnews/research/display.aspx $? \mathrm{id}=12785>$

Greenstein, Shane. (2007). "Economic Experiments and Neutrality in Internet Access." National Bureau of Economic Research. Retrieved from:

<http://nber.org/papers/w13158.pdf> 
Hahn, Robert W. and Wallsten, Scott. (2006). "The Economics of Net Neutrality." Economists' Voice. 3(6), 1-7.

Hass, Douglas A. (2007). "The never-was-neutral net and informed end uses can end the net neutrality debates." The Berkeley Electronic Press (bepress) Legal Series, Paper 1979.

Jordan, Scott. (2009). "Implications of Internet Architecture upon Net Neutrality." Acm Transactions on Internet Technology, 9(2), 5:1-5:28.

Lenard, T., \& Scheffman D (2006). "Distribution, vertical integration and the net neutrality debate." In T. Lenard, \& R. May (Eds.), Net neutrality or net neutering - should broadband services be regulated? (pp.1-24). Springer US.

Lessig, Lawrence. (2001). The future of ideas: The fate of the commons in a connected world. New York: Random House.

Lithgow, Michael. "Myth-busting the Internet: the truth about throttling, congestion and usage-based billing." Coop Media de Montreal. Retrieved from: <http://montreal.mediacoop.ca/story/myth-bustinginternet/7422>

Meinrath, S, \& Pickard, V. (2008). "The new network neutrality: criteria for internet freedom". International Journal of Communications Law \& Policy, (12), Retrieved from: <http://ijclp.net/files/ijclp_web-doc_1012-2008.pdf>

Mosco, Vincent. (1990). The mythology of telecommunications deregulation. Journal of Communication 40(1), 36-49.

Mosco, Vincent. (2004). The digital sublime: Myth, power, and cyberspace. Cambridge, MA: MIT University Press.

Mosco, Vincent. (2009). The political economy of communication: Rethinking and renewal $(2$ ed). Thousand Oaks, CA: Sage.

Mudhar, Raju. (December 2009). Rogers on demand but who will demand it? The Toronto Star. Retrieved from: <http://www.thestar.com/entertainment/television/article/732821-rogers-on-demand-online-but-who-ll-demand-it>

Owen, B., \& Rosston G. (2003). "Local broadband access: primum non novere or primum processi? A property rights approach." In T. Lenard, \& R. May (Eds.), Net neutrality or net neutering - should broadband services be regulated? (pp.163194). Springer US. 
Persaud, Christine. “Bell silently closes online video store”. (June 2009). Market news. Retrieved from:

<http://www.marketnews.ca/LatestNewsHeadlines/BellSilentlyClosesOnlineVide oStore-UPDATED2!.html>

Public Interest Advocacy Centre. (2009). "Staying neutral: Canadian consumers and the fight for net neutrality." Canadian Cataloguing and Publication Data. Retrieved from:

<http://piac.ca/downloads/NN_Report_MASTER_FINAL_website.pdf>

Schwartz, S.H. (1992). "Universals in the Content and Structure of Values: Theoretical Advances and Empirical Tests in 20 Countries." In M.P. Zanna (Ed.), Advances in Experimental Social Psychology, Vol. 25.

Schwartz, S.H. (1994). "Are There Universal Aspects in Structure and Contents of Human Values?" Journal of Social Issues (50) 4: 19-45.

Schwartz, S.H. (2007). "Value Orientations: Measurement, Antecedents and Consequences Across Nations." In J. Rogers, et al (Eds.), Measuring Attitudes Cross-Nationally: Lessons from the European Social Survey: $\underline{169-203 .}$

Singer, Hal J. and Litan Robert E. (2007). "Unintended Consequences of Net Neutrality Regulation." Journal of Telecommunications and High Technology Law.

Sorensen, Chris. (2009, July 13). Don't regulate traffic management, internet providers argue. The Toronto Star. Retrieved from:

<http://www.thestar.com/article/665248>

Speta, James B. "A Common Carrier Approach to Internet Interconnection." North Western University website. Retrieved from:

$<$ http://www.law.northwestern.edu/faculty/fulltime/speta/papers/CC\%20final.pdf

Woodrum, E. (1984). "Mainstreaming Content Analysis in Social Science:

Methodological Advantages, Obstacles, and Solutions." Social Science Research, Vol. 13: 1-19.

Wu, Tim. (2003). "Network neutrality, broadband discrimination." Journal of

Telecommunications and High Technology Law, 2, 141-179.

Yoo, Christopher. (2006). “Network neutrality and competition policy: a complex Relationship”. In T. Lenard, \& R. May (Eds.), Net neutrality or net neutering should broadband services be regulated? (pp.25-71). Springer US. 